\title{
EL PATRIMONIO TERRITORIAL Y PAISAJISTICO DE LEITARIEGOS: DE LA MIRADA INTELECTUAL A LA PRIMERAACCIÓN OFICIAL CONTEMPORÁNEA
}

\author{
Carmen Rodríguez Pérez \\ Departamento de Geografía de la Universidad de Oviedo \\ crperez@uniovi.es \\ Juan Sevilla Álvarez \\ Departamento de Geografía de la Universidad de Salamanca' \\ Departamento de Geografía de la Universidad de Oviedo \\ sevillajuan@uniovi.es
}

\section{RESUMEN}

El puerto de Leitariegos y el macizo del Cueto Arbás componen una unidad geográfica con importancia ecológica, estética, etnográfica e histórica ubicado en la montaña occidental de Asturias y León (Noroeste de España). Ha sido objeto de acciones oficiales de distinto tipo (explotación turística, protección del patrimonio natural y cultural). El objetivo es identificar y analizar los valores que, destacados en el discurso de actores intelectuales e institucionales durante siglos, conducen al germen de un proceso de patrimonialización.

Palabras clave: paisaje, montaña, patrimonialización, Leitariegos.

\section{ABSTRACT}

The pass of Leitariegos and massif of Cueto Arbás are placed in western mountains of Asturias and León (NW of Spain) and have ecological, aesthetic, ethnographic and historical importance. They have been included in different official actions (such as tourist develop-

Fecha de recepción: julio 2015.

Fecha de aceptación: julio 2016.

1 Durante la fase de elaboración del trabajo el autor se adscribe al Departamento de Geografía de la Universidad de Salamanca; posteriormente, durante la fase de revisión del artículo, se ha producido la incorporación al Departamento de Geografía de la Universidad de Oviedo. Ambos autores trabajan en el Grupo de Investigación ARPE y en el Observatorio del Territorio de la Universidad de Oviedo. 
ment or natural and cultural heritage protection). This work aims to identify and analyse different values which, contained in both intellectual and institutional attitude during centuries, lead to the origin of a heritage making process.

Keywords: landscape, mountain, heritage making, Leitariegos.

\section{INTRODUCCIÓN}

La noción de 'patrimonio', originariamente vinculada a planteamientos marcados por consideraciones estéticas y muchas veces apoyados en el interés y la trascendencia histórica del monumento, de la obra de arte, ha evolucionado durante la pasada centuria hasta englobar todo género de realidades materiales e inmateriales asociadas a prácticas colectivas: manifestaciones folklóricas, artes escénicas, procedimientos artesanos, instalaciones manufactureras e industriales, etc. La cuestión patrimonial aparece así ligada a inquietudes que tienen que ver con la voluntad de una comunidad de proteger, conservar y transmitir toda expresión valiosa de su memoria o de sus prácticas colectivas (Béghain, 1998; Poulot, 1998).

El patrimonio, construido socialmente, conlleva un sentido y valores relevantes para la colectividad (Bouisset y Degrémont, 2010). Debe tenerse en cuenta, además, que una nueva reacción de la sociedad con respecto a la naturaleza, incluso una reinvención de esta relación del hombre con la naturaleza (Berdoulay, 2004), junto a la emergencia del medioambiente como valor de referencia (Béghain, 1998), han contribuido a la evolución del concepto dando lugar a una dimensión territorial y paisajística del patrimonio (Berdoulay, 1992; Degrémont, 1998). La consideración de lo que es patrimonial se extiende así a territorios caracterizados por distintas cualidades (representatividad, singularidad, rareza, estado de conservación), comenzando a incluirse en reflexiones científicas e institucionales acerca de la preservación de la naturaleza y la importancia del paisaje como un bien público (Guillaume, 1990; Béghain, 2012).

Determinados espacios adquieren entonces la cualidad de patrimonio como resultado de la difusión de prácticas de reconocimiento, estudio o disfrute por parte de actores sociales, científicos e institucionales, en iniciativas individuales o conformando organizaciones y asociaciones. Durante campañas de exploración, excursiones o viajes, en trabajos de campo o en prácticas recreativas, estos actores identifican valores ecológicos, estéticos, pedagógicos, simbólicos, etc. Y promueven su conocimiento con la intención de que, por su interés o relevancia social, sean reconocidos, contemplados, compartidos, protegidos o, según los actores, aprovechados como un recurso económico (Bouisset et al., 2010).

Este tipo de proceso ha sido particularmente notorio en sectores montañosos del centro y suroccidente de Europa desde finales del siglo XIX. El interés intelectual por la montaña desarrollado durante el Siglo de las Luces había determinado ya un cambio de actitud, iniciado con el Humanismo renacentista, hacia este tipo de medio; contrarrestando aquella otra mirada popular influenciada por el miedo y los mitos (Martínez de Pisón, 2004). Después, el movimiento romántico consolida categorías estéticas que dan lugar a una nueva sensibilidad hacia la naturaleza y refuerzan la valoración del paisaje montano: cobran fuerza en pintores y literatos, eruditos y viajeros curiosos, entre otros colectivos, las emociones y los estímulos generados por la visión bucólica de lo «pintoresco» o majestuosa de lo «sublime». Al tiempo, se intensifican las campañas de estudios topográficos, geológicos, botánicos, etnográficos, etc. para la mejora 
del conocimiento científico de la media y alta montaña; campañas que no solamente acrecientan la atención intelectual pues, al contribuir al conocimiento de estos espacios, incentivan la difusión del excursionismo y las prácticas deportivas (muy frecuentes a partir de la creación de asociaciones y clubes en las últimas décadas del siglo XIX).

Podemos afirmar, en definitiva, que la percepción del carácter excepcional de estos espacios se apoya en varios factores confluyentes: la voluntad científica de profundizar y sistematizar el conocimiento de la montaña; el ideal de exploración de sectores poco accesibles y apenas conocidos; y la concepción de este tipo de medio como fuente de regeneración física y moral, además de consideraciones sobre la belleza asentadas en conceptos estéticos particularmente evocados desde el período decimonónico (Maderuelo, 2007; Ortega, 2010; Gómez, 2013; Martínez y Sevilla, 2013).

Esta interacción de inquietudes y saberes favorece o inspira, además, la aplicación de las primeras acciones oficiales estatales de protección de la naturaleza, a finales del siglo XIX y principios del siglo XX. La valoración del paisaje de montaña como patrimonio está presente en ellas, aunque de modo más explícito o implícito en función del peso que las consideraciones culturales, estéticas y éticas tienen en cada región y de la terminología utilizada en cada caso.

La consolidación de esta consideración patrimonial del territorio y del paisaje se produce, con todo, al avanzar las décadas centrales del siglo y se percibe como generalizada desde la «Convención para la protección del patrimonio mundial» de la UNESCO, celebrada en Paris en 1972. Se concreta entonces una valoración de la naturaleza compartida universalmente, apoyada en criterios científicos y estéticos (Serrano, 2012; Gómez, 2013). También en esta época, en parte por las determinaciones de este organismo internacional, se generaliza el uso del término ‘patrimonio' aplicado al objeto de la ciencia geográfica (con anterioridad muchos planteamientos y prácticas plenamente patrimoniales por su carácter no hacen uso del propio término).

El proceso se reafirma a finales de la pasada centuria con la incorporación de la figura de «paisaje cultural» en las directrices operativas de la Convención del Patrimonio Mundial, registrada en 1992 (Rodrigo, 2012); y en el cambio de siglo, a partir del Convenio Europeo del Paisaje, firmado en Florencia en el año 2000 (ratificada por España en 2008), que concibe el paisaje como «componente fundamental del patrimonio natural y cultural europeo, que contribuye al bienestar de los seres humanos».

En el presente artículo ${ }^{2}$ nos proponemos analizar el origen de la patrimonialización de un espacio de notable valor ecológico, estético, etnográfico e histórico ubicado en la montaña occidental de Asturias y León (Noroeste de España): el puerto de Leitariegos y el macizo del Cueto Arbás (véase Figura 1). Se trata de un conjunto montañoso integrado por la depresión del puerto y las dos alineaciones que la enmarcan por el Noreste y el Suroeste, incluyendo la parte inferior de estas vertientes y los valles adyacentes (véase Figura 2). Su paisaje puede ser considerado de dominante natural dada la importancia que tienen los elementos naturales en su configuración. Nos encontramos ante un ejemplo de paisaje de montaña en el que se puede reconocer una superposición de formas de modelado correspondientes a diferentes períodos

2 Este trabajo se ha elaborado en el marco del proyecto de investigación «Paisajes patrimoniales de la España Atlántica y Navarra» (clave de referencia: CSO2012-39564-C07-05; Investigadores Principales: Dr. D. Eugenio Ruiz Urrestarazu -hasta el 30-11-2014- y Dra. Dña. Ma Cruz Porcal Gonzalo -desde 1-12-2014-), correspondiente al subprograma de proyectos de investigación fundamental no orientada, en el marco del VI Plan Nacional de Investigación Científica, Desarrollo e Innovación Tecnológica. 
morfogenéticos, lo que permite plantear una reconstrucción evolutiva del relieve. Atendiendo a aspectos biogeográficos, contiene un mosaico vegetal diverso que resulta de la distribución de la vegetación en pisos bioclimáticos, matizada en alguna medida por el aprovechamiento ganadero. Y es que, en efecto, junto a la importancia de los elementos naturales, no debemos obviar la impronta de las actividades agroganaderas de las comunidades locales ni la trascendencia del puerto para las comunicaciones del occidente de Asturias y León. Constituye, efectivamente, un paso clave de un itinerario histórico: el Camín Real de Leitariegos.

En las últimas décadas el conjunto de Leitariegos y el Cueto Arbás ha sido protegido por sus valores excepcionales de tipo ambiental y ecológico, subyaciendo el paisaje en las declaraciones de protección (no sobresale como argumento principal). El área meridional, en la provincia de León, forma parte del valle de Laciana, que se incluye en la Zona de Especial Conservación (ZEC) «Alto Sil», en la Zona de Especial Protección para las Aves (ZEPA) «Alto Sil» y en el Espacio Natural «Sierra de Ancares». Además, el valle de la Laciana es Reserva de la Biosfera. En cuanto al sector septentrional, perteneciente a Asturias, se encuentra igualmente amparado por distintas figuras: Reserva Natural Parcial de Cueto de Arbas, Zona de Especial Conservación (ZEC) de Fuentes del Narcea, Degaña e Ibias, Zona de Especial Protección para las Aves (ZEPA) de Fuentes del Narcea, Degaña e Ibias, Parque Natural de las Fuentes del Narcea, Degaña e Ibias y Reserva de la Biosfera del mismo parque. A ello se añade la catalogación del complejo glaciar del Puerto de Leitariegos como Lugar de Interés Geológico (LIG 0-95) en el Catálogo del Patrimonio Geológico elaborado por el Instituto Geológico y Minero de España; y la inclusión del Camín Real de Leitariegos en el Programa de Caminos Naturales del Ministerio de Medio Ambiente y Medio Rural y Marino así como en el Inventario de Patrimonio Cultural de Asturias.

Estas actuaciones de la Administración en el ámbito de la protección no han logrado resolver, sin embargo, la incompatibilidad de usos habitual en espacios patrimoniales de uso agrario tradicional muy frecuentados debido a la promoción turística (marcha a pie, deportes de invierno, etc.) o afectados por la presión de las actividades extractivas (mina a cielo abierto).

El objetivo del trabajo es, en este caso, caracterizar las actividades de aquellos individuos y colectivos que han promovido la difusión del conocimiento de este sector montañoso, favoreciendo o interviniendo en el origen de un proceso de puesta en valor patrimonial. Se trata, en definitiva, de conocer las prácticas, los discursos y las representaciones de tales actores con el fin de comprender por qué se valorizan el puerto de Leitariegos y macizo del Cueto Arbás, y cómo se construye y manifiesta su patrimonialización.

El estudio parte de la primera distinción institucional realizada en este espacio, un privilegio real otorgado por Alfonso XI en 1326 a los habitantes del puerto en razón del mantenimiento de labores asistenciales en este paso elevado. A continuación, analizamos la obra científica, divulgativa, literaria y gráfica de intelectuales adscritos a diversas ramas del saber (Geología, Botánica, Etnografía, etc.), viajeros y excursionistas, que se adentraron en este territorio con el afán de conocerlo, disfrutarlo y divulgarlo desde finales del siglo XVII hasta el momento en que se producen las primeras acciones oficiales de puesta en valor contemporáneas, en los primeros años de la década de 1970. Éstas tienen que ver con el inicio de la construcción de una estación de esquí y la promoción turística del espacio del puerto, con anterioridad a la declaración de figuras de protección. Verificando la permanencia de su discurso, pretendemos reconocer en aquel legado el germen del proceso de patrimonialización del espacio de montaña que nos ocupa. 


\section{Figuras 1 y 2}

A LA IZQUIERDA, MAPA DE LOCALIZACIÓN DEL PUERTO DE LEITARIEGOS Y DEL MACIZO DEL CUETO ARBÁS. A LA DERECHA, EL PUERTO DE LEITARIEGOS OBSERVADO DESDE LAPARTE BAJA DE LA VERTIENTE NORORIENTAL. SE RECONOCEN EL PUEBLO -EN PRIMER TÉRMINO-, LAS INSTALACIONES DE LA ESTACIÓN DE ESQUÍ-A LA IZQUIERDA,

AL FONDO-, Y EL SECTOR MERIDIONAL DEL MACIZO DEL CUETO ARBÁS -EN LA PARTE SUPERIOR DERECHA.

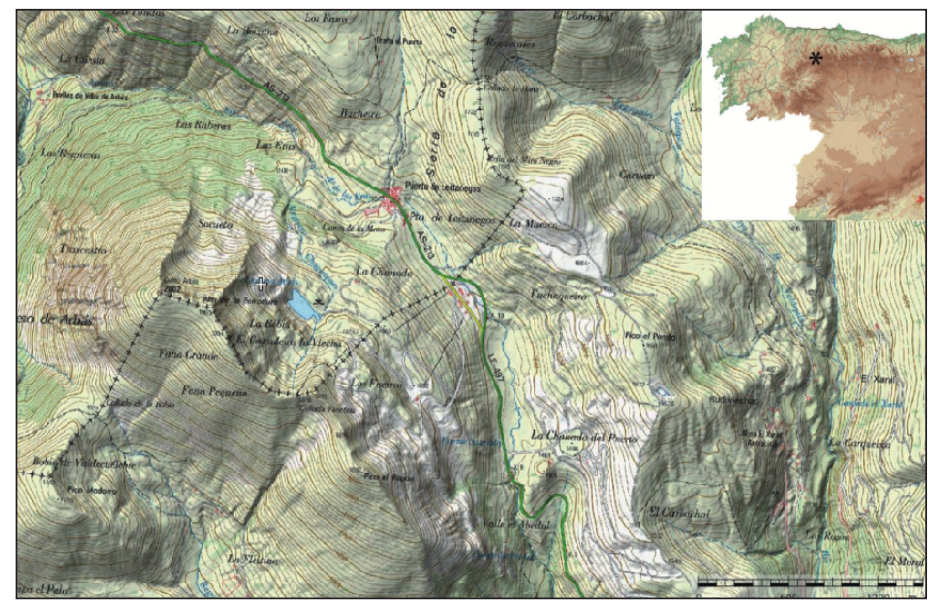

Fuente: IGN: MTN25-76-III Y 101-I.

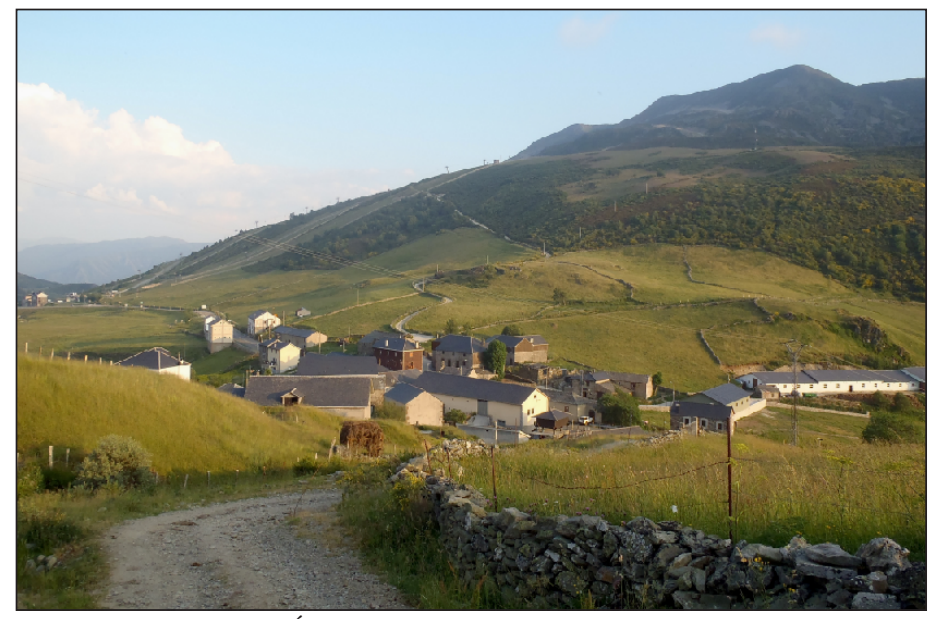

Fotografía: Juan Sevilla Álvarez.

\section{EL RECONOCIMIENTO REAL A INICIATIVAS VECINALES CENTENARIAS}

La relevancia histórica del puerto de Leitariegos como paso destacado en el sector occidental de la divisoria cantábrica se remonta muy probablemente a la Antigüedad. Diversos estudios señalan que en época romana canalizaba el transporte de mercancías entre los sectores con explotaciones auríferas del occidente asturiano y las comarcas de Laciana y el Bierzo, en León (Ruiz de la Peña, 1979; Rabanal, 1984; Santos, 1988; González, 2011). 
En la Edad Media este paso natural gana en celebridad al tiempo que aumenta la circulación de personas y mercancías. Lo demuestra la existencia de alberguerías u hospitales creados, o al menos documentados, a partir de mediados del siglo XII: los de Ferrera, Leitariegos, Cafrenal y Santa María de Brañas, dependientes del monasterio de Corias (situado en el valle medio del Narcea, en Asturias) y dotados de recursos propios para mantener la prestación de servicios benéficos. Éstos consistían en el auxilio, la asistencia, el acompañamiento y la protección a caminantes, incluida la disponibilidad de cama -para el descanso o la pernocta-, comida y cuidados sanitarios, lo que no debía de ser inhabitual dada la dureza del clima de montaña en esta zona, con temperaturas extremas, nieblas frecuentes, lluvias persistentes y nieve abundante (Ruiz de la Peña, 1979³ Ocampo, 2013).

Las relaciones entre los territorios del suroccidente asturiano y la comarca de Laciana ganaron impulso con las fundaciones de la Puebla de Cangas, en 1255, y la Puebla de San Mamés (Villablino), en 1270, en el marco de la política repobladora de Alfonso X, y con la consiguiente celebración de ferias y mercados en estos nuevos núcleos. A las anteriores, vinieron a sumarse además las fundaciones de Luarca, Navia y Castropol en la costa occidental asturiana durante el último tercio del siglo XIII, lo que incrementó el interés del contacto comercial entre los pueblos de ambas vertientes de la Cordillera Cantábrica por el estímulo que suponía la adquisición de productos llegados por mar.

La relevancia y el reconocimiento a la labor asistencial desempeñada en el puerto de Leitariegos se refuerza, por tanto, con el aumento del comercio astur-leonés. Y lo hace hasta el punto de motivar la concesión de un privilegio real a los habitantes de Leitariegos, Brañas, Trascastro y todos los lugares del puerto, otorgado por Alfonso XI el 14 de abril de $1326^{4}$. A partir de entonces, los vecinos se beneficiaron de un estatuto jurídico excepcional que suponía la exención de cargas impositivas (fiscales, señoriales así como de tipo militar); de esta manera se pretendía incentivar su permanencia en el puerto a lo largo del año, soportando las duras condiciones de vida que aquel lugar imponía, para garantizar con ello su dedicación al acondicionamiento de los caminos y a la guía y ayuda a caminantes. Serán las principales actividades en el puerto junto a la caza, la ganadería y la arriería, viéndose esta última particularmente favorecida por dichas ventajas tributarias, de ahí que aumentase la importancia

3 El estudio de Juan Ignacio Ruiz de la Peña, Catedrático de Historia Medieval en la Universidad de Oviedo, resulta de imprescindible consulta para conocer la trascendencia de este lugar montano en la Edad Media. Pero, además, su actividad en Leitariegos interesa dado que el propio investigador puede ser considerado actor de la patrimonialización del puerto y del macizo del Cueto Arbás, en tanto que continuador de la corriente de intelectuales que, sobre todo desde el siglo XIX, exploran estos parajes y difunden el conocimiento de sus valores naturales y etnográficos. Más adelante nos referimos a esta faceta del trabajo del profesor asturiano.

4 Con anterioridad -tal como refiere Jovellanos en el Cuaderno VI de su Diario (relato correspondiente al 11 de octubre de 1796) - la tradición oral recoge que Doña Urraca había concedido a los vecinos de Leitariegos una compensación anual (cincuenta fanegas de trigo) en agradecimiento al amparo que le habían proporcionado con motivo de un temporal de nieve, con la condición de que continuasen habitando aquellas tierras. La noticia de Doña Urraca, como la del privilegio concedido por Alfonso XI, es recogida en numerosos trabajos posteriores, entre ellos el del etnógrafo agustino César Morán Bardón en 1925 (Por Tierras de León. Historia, costumbres, monumentos, leyendas, filología y arte). Del texto de Morán, e igualmente refiriéndose al privilegio de Leitariegos, da cuenta Florentino Agustín Díez González en 1946 (Laciana. Memoria de su antiguo y patriarcal Concejo). De la relación de la realeza con este y otros itinerarios asturleoneses, así como del interés que suscitó entre numerosos colectivos (en parte referenciados en este trabajo), informa igualmente Julio Álvarez Rubio en Aventureros del tiempo. Leyenda de caminos y de poderosas razones para viajar (2004). 
de las recuas hasta bien entrada la Edad Contemporánea (en el siglo XIX existía una línea regular que llegaba a Madrid y a mediados de la misma centuria se fusionaron los principales arrieros del puerto en «La Compañía»).

El privilegio fue ratificado por la Corona durante más de cinco siglos, no siendo abolido hasta 1879, año en que, sobre el ya considerado Camino Real de Madrid a Asturias, se inaugura la carretera que une las dos cabeceras comarcales. Y con ésta las instituciones consideraron superados los riesgos y las dificultades que motivaban las atenciones de los pobladores del puerto; de ahí que perdiera efecto la principal razón del mantenimiento de la distinción jurídica (Ruiz de la Peña, 1979; Grupo Ecologista Cangués Azor, 2012).

En el tiempo en que se construye la carretera comienzan a utilizarse las diligencias -sobre todo para viajeros- y los carromatos, siendo destacable la línea con destino a León que establece Cándido Cosmen, de la Casa Provisor. Por el puerto pasaría igualmente la línea de Ponferrada a Cangas, gestionada por los miembros de la Casa La Fuente -también Cosmen, familia que también se dedicaba con anterioridad a la arriería-, algunos de los cuales se encuentran en el origen de los servicios de transporte con vehículos de motor en Asturias. La profesión de carretero dará paso de este modo a la de camionero o conductor de ómnibus, siendo en 1913 cuando empiezan a circular los primeros coches de línea que atraviesan el puerto (Grupo Ecologista Cangués Azor, 2012; Ocampo, 2013).

Se puede concluir, en definitiva, que las dificultades orográficas y meteorológicas asociadas a este paso natural y la necesidad de superarlas debido a su creciente interés para la actividad mercantil, terminan por generar una rama de actividad que, en su evolución histórica, acaba por transformarse en uno de los negocios más prósperos de la economía regional (Ocampo, 2013). Con todo, en este largo proceso, los habitantes adquieren una identidad territorial determinada por modos de vida y trabajo estrechamente ligados a las condiciones del medio en el que viven (Béghain, 1998); identidad que se encuentra en la base de la construcción de una imagen patrimonial de Leitariegos y su conjunto montañoso.

\section{EL ÁMBITO INTELECTUAL Y LA CONSIDERACIÓN DE LEITARIEGOS COMO ESPACIO DE MONTAÑA EXCEPCIONAL}

Las prácticas individuales y colectivas de agentes diversos, fundamentalmente científicos, excursionistas y viajeros, revisten importancia en el surgimiento de una nueva mirada hacia la montaña a finales de la Edad Moderna e inicios de la Edad Contemporánea; una mirada que motiva la frecuentación de los más variados macizos montañosos de nuestro continente, dejándose notar de manera notable en el Suroeste del mismo, y anima la publicación de escritos y materiales gráficos que subrayan las cualidades y valores naturales, culturales, estéticos, etc. de los lugares montanos visitados. Precisamente, esos trabajos confluyen con el paso de las décadas para sugerir directamente, o bien inspirar indirectamente, acciones institucionales de protección oficial, pero también de promoción turística, de muchos sectores montañosos, estando por lo tanto en la base del proceso de puesta en valor patrimonial de estos espacios. En estas líneas exponemos cómo el caso del puerto de Leitariegos y del macizo del Cueto Arbás, al margen del singular valor histórico explicado en el apartado anterior, comparte rasgos comunes con otros sistemas montañosos continentales en cuanto al origen de la difusión de su conocimiento como espacio excepcional. 
Una de las primeras menciones significativas del Cueto se remonta al siglo XVII y corresponde al historiador y religioso asturiano, también maestro y docente universitario, Luis Alfonso de Carvallo, natural de la misma comarca del Narcea -nace en el barrio de Entrambasaguas, en Cangas- y autor de Antigüedades y cosas memorables del Principado de Asturias. Publicada varias décadas después de su muerte, en 1695, esta obra sigue los principios del Humanismo italiano en cuanto a la voluntad de rigor y puede considerarse la primera historia general de Asturias (Carvallo, 1695; López, s.f. a).

En el «Título Sexto. De los Vandalos, Alanos y Suebos», refiriéndose al terreno de los enfrentamientos entre estos pueblos, Carvallo señala:

«[...] con esto, se vinieron a encontrar en los Montes [...], que ahora se llaman los Cuetos de Arbas, junto al Puerto de Leitariegos, que dividen los Concejos de Cangas, y Laciana; y el valle que desciende de estos Montes se llama el Valle de Arbas, en el Concejo de Cangas de Tineo 5 . Y aviendo venido a las manos, fueron vencidos los Suebos, y se acogieron desvaratados a la cumbre del collado, que llaman el Cueto de Arbas, que es el más soberbio, y levantado de todas aquellas montañas, y de todas partes se sube a la cumbre con gran dificultad, y en lo alto es muy espacioso y llano, con una laguna grande, y muchos guijarros redondos[...]» (Carvallo, 1695).

Además de referirse a la localización en la divisoria de aguas, aparecen ya apreciaciones sobre el terreno de la laguna o el volumen y la majestuosidad del Cueto, bien destacado sobre las montañas circundantes y con una marcada ruptura de pendiente entre las diferentes vertientes y la cima.

\section{III.1. La mirada intelectual a la montaña en el Siglo de las Luces: Gaspar Melchor de Jovellanos en la comarca del Narcea}

Ya se ha aludido anteriormente al cambio de actitud que el Siglo de las Luces consolida respecto al interés de la sociedad por el medio montano. En el caso del puerto de Leitariegos y el macizo del Cueto Arbás, interesa la «Descripción de la Real Jurisdicción de Leitariegos o Lazariegos» recogida por uno de los más destacados representantes españoles de la Ilustración: Gaspar Melchor de Jovellanos. Nos encontramos ante un intelectual y político inquieto por el desarrollo territorial, que no cesó en su empeño de recorrer, reconocer y analizar in situ los principales recursos de su Asturias natal con el fin de apuntar vías de modernización social y económica (González, 2011). En este sentido, en el Cuaderno Sexto de su Diario (años 1795 y 1796) relata un viaje realizado a la comarca del Narcea e incorpora una interesante nota acerca del puerto y su entorno, correspondiente a las observaciones que le aporta el escribano Manuel Folgueras.

Se trata de una sugerente caracterización del conjunto del puerto de Leitariegos y el macizo del Cueto Arbás, no exenta, quizás, de idealización. Ensalza la elevación del macizo, que considera uno de los más importantes de Europa. Se trata muy probablemente de una

5 Antigua denominación de la cabecera municipal y comarcal hasta 1927, en que ya se denomina Cangas del Narcea. Cabe señalar, no obstante, que El Puerto, junto con Trascastro, Brañas de Abajo y Brañas de Arriba, formaron municipio distinto del cangués entre 1821 y 1921. 
afirmación fruto de la impresión causada por el mantenimiento de cierta cantidad de nieve incluso en época estival y de la percepción visual que provoca la prominencia de la cumbre principal. Por otro lado, describe la topografía característica del puerto, más llana y abordable que la de las cumbres circundantes, en el límite entre tierras leonesas y asturianas y en la divisoria de aguas entre las cuencas del Narcea y del Sil:

«Hállase al extremo del concejo de Cangas de Tineo y en él comprendida. Su montaña es una de las más elevadas y encumbradas de la Europa, y el lugar del Puerto consistente en una llanura por una abertura que en aquel paraje hace la montaña; es extremo y divisoria del Principado de Asturias con el reino de León por aquella parte, de manera que las aguas que bajan al Puerto desde las montañas es parte del origen del río Narcea por curso natural desde su nacimiento, pero si las desvían para riego de la pradería, se dirigen a Lacenada y se unen al del Sil, que quien también son origen en este caso o parte [...]» (Jovellanos, 1999).

Se refiere al poblamiento y al número de vecinos, destacando sus actividades predominantes: el mantenimiento de ganado de varias especies, característico del sistema agrario tradicional en la montaña asturiana, y la importancia de la arriería, vinculada al caballar y cuyo auge se comenta más arriba:

«Compónese de cuatro lugares con cincuenta y siete moradores: Trascastro, Brañas de Arriba, Brañas de Abajo y El Puerto; y en este nada se siembra ni coge, sino yerba para manutención de ganados vacunos, lanares y caballar, por ser todos ellos arrieros, de cuyo oficio se mantienen [...]» (Jovellanos, 1999).

También se fija en los terrenos en que se encuentra la laguna de Arbás, en las proximidades del pico homónimo. En ellos ve una hoya que acuna un depósito de agua de cierta extensión y profundidad, provechoso para la riqueza de los pastos de altura:

«Se encuentra cerca de la cumbre de aquella montaña eminente llamada el Pico de Arbas un poco de término a manera de cárcaba o cuna, en donde se registra un piélago de agua, que titulan la Laguna de Arbás, con bastante extensión y profundidad, que de invierno la rebosa y aprovechan su agua para riego de prados con vertiente al Narcea [...]» (Jovellanos, 1999).

\section{III.2. La sistematización del conocimiento científico de la montaña: representaciones de Leita- riegos y del Cueto Arbás}

Los efectos del progreso científico, que tiene base ya en época renacentista, beneficiado además por los avances tecnológicos que posibilita el incipiente proceso de industrialización, se dejan notar en la proliferación de campañas dirigidas a profundizar en el conocimiento científico de la montaña. Así, muchos de los primeros acercamientos a la media y alta montaña en los inicios de la Edad Contemporánea tienen un carácter predominantemente científico y responden al desarrollo de proyectos geológicos, topográficos, botánicos, etc. En este contexto se enmarca 
el viaje de Michel Charles Durieu de Maisonneuve, oficial de infantería y botánico francés, a la región asturiana en 1835, animado por su compatriota Jean-Baptiste Bory de Saint-Vincent, capitán del ejército y reconocido naturalista (Castañón y Quirós, 2004). Éste le habría sugerido centrar sus estudios en la «prolongación occidental de nuestras grandes montañas meridionales» (Académie des Sciences, 1836); recomendación que igualmente alcanza al también naturalista Jacques Gay, implicado en la misma iniciativa botánica al recibir posteriormente el encargo de estudiar buena parte de los ejemplares de plantas recogidos en Asturias. De este modo, Durieu de Maisonneuve seguía la estela de científicos vinculados al ejército francés particularmente involucrados en completar el conocimiento de la flora de nuestro territorio y de su distribución geográfica exacta. Estimaban muy destacable la diversidad biogeográfica del país, que llegaban a considerar como el «más rico de Europa» en términos botánicos (Gay, 1958).

Durieu se desplaza desde el área central al suroccidente asturiano, realizando sucesivas paradas, hasta llegar a la villa de Cangas. Y desde allí realiza varias excursiones a la cabecera del valle del Naviego y al macizo del Cueto Arbás, donde se interesa por la vegetación en la zona de la laguna y completa su exsiccata de plantas asturianas (Rivas y Rivas, 1959; Grupo Ecologista Cangués Azor, 2012) ${ }^{6}$. De esta experiencia nos deja suculentos textos Jacques Gay en «Viaje botánico de Durieu por Asturias emprendido en el año 1835» ${ }^{7}$ a partir de la correspondencia mantenida entre ambos:

«Por encima de Trascastro el ya en sí angosto valle del Naviego se estrecha más y más, terminando por reducirse a una profunda y escarpada grieta, del todo infranqueable, por la que se precipita el río, procedente del lago que hay en el Cueto de Arbas. Allí, en los rincones umbrosos y en las empapadas rocas laterales $[\ldots] \gg($ Gay, 1958).

Se anticipan aquí algunos temas comunes de este tipo de relatos en medio montano: la angostura del valle en las partes más altas, la inclinación de las vertientes, la sensación de inaccesibilidad y las dificultades del tránsito, el sonido y la fuerza del agua discurriendo entre materiales de arrastre en el nacimiento del curso fluvial, los ambientes húmedos y sombríos, ...

«El Naviego se despeña por el ángulo nordeste de la dicha laguna, por un cauce tan exiguo al principio que se puede abarcar abriendo las piernas, pero que no tarda en hacerse muy profundo y angosto. [...] allí las orillas se alzan casi a pico, erizadas agriamente de fragmentos rocosos, mientras el río, por completo sepultado bajo las piedras que han ido cayendo por ambas márgenes, deja conocer su presencia únicamente por el murmullo de sus aguas ocultas [...]» (Gay, 1958).

6 Durieu inicia un camino que posteriormente será completado por otros estudiosos de la vegetación (Bourgeau, 1847; Pierre Allorge, 1927 y Font Quer, 1935) tal como recogen Rivas Goday y Rivas Martínez en su artículo «Una visita a la Laguna de Arvas (Leitariegos)», publicado en Anales del Instituto Botánico A.J. Cavanilles (artículo $\mathrm{n}^{\circ} 9, \mathrm{n}^{\circ}$ 16, 1959). Estos autores citan el trabajo Plantae Asturicae exsiccatae, anno 1835 lectae del botánico francés. Del mismo artículo interesa, además, el paralelismo que sus autores establecen «entre la comarca del Arva (con excepción de las zonas calizas, hacia Somiedo) y el Guadarrama y Gredos, claro está mucho más continentales las de la alineación central».

7 Aparece en el número 6 del Suplemento de Ciencias del Boletín del Instituto de Estudios Asturianos (Oviedo, 1958). El original «Duriaei Iter Asturicum Botanicum, Anno 1835 Suceptum» se publica en 1836, en Annales de Sciences Naturelles. 
Por encima, hacia el Sur, destaca la cumbre del Cueto Arbás, que

«[...] separado completamente de las cumbres próximas, semeja una pirámide truncada cuyas caras se alzan escarpadísimas por todas partes. Es difícil, sobre todo, la mitad superior, ceñida por incómodos pedregales movedizos y en absoluto innaccesible por el este y norte, con lo que ha de atacársela por el duro repecho del sudeste. [...] En esta ladera oriental, un poco por debajo de la cumbre, todavía quedaban restos de un nevero el 17 de julio de 1835, que habían desaparecido una semana después [...]» (Gay, 1958).

El texto de Gay recoge, como hacía el de Carvallo, la forma singular del Cueto, de aspecto geométrico (con la culminación achatada y abruptas paredes). Durieu se habría fijado con cierto detalle en éstas: cubiertas de pedreros en varios flancos e incluso de algún nevero ya avanzado el verano. La permanencia de la nieve sigue llamando la atención de quienes se detienen a conocer este conjunto montañoso de la Asturias suroccidental. En todo caso, queda patente la difícil subsistencia en aquel puerto, en el que, según Gay, habría sido extrema la penuria de no haberlo atravesado el camino de herradura que generaba tránsito mercantil desde antiguo, habiendo motivado en época medieval la creación de alberguerías y, con la función asistencial de éstas, el estatuto concedido por el rey castellano:

«Por manera ninguna se podrían defender en la vida si no consiguieran ciertas ganancias con el tránsito mercantil, pues ejercen con sus caballerías el oficio de arrieros, transportando personas y bultos desde Cangas al valle del Sil y viceversa. [...] Tenidas en consideración todas las circunstancias regionales, supongo que esa altitud será, por lo menos, de 700 toesas; lo que deduzco no solamente de la ausencia local de la berza (siendo así que se la ve cultivada media legua más abajo, en Brañas de $\mathrm{Arriba}^{8}$ ), sino también de la innivación prolongadísima: le dijeron allí a Durieu que durante cuatro meses largos hay en el pueblo tanta nieve que las casitas quedan casi del todo sepultadas y la comunicación ha de realizarse por túneles perforados en la misma nieve o por ventanas abiertas en lo alto de los techos [...]» (Gay, 1958).

Con posterioridad se conoce el interés de otros científicos destacados que también se acercaron a Leitariegos. Por ejemplo, hay noticia de una célebre visita realizada en agosto de 1914 por el geólogo y paleontólogo Eduardo Hernández-Pacheco, el premio Nobel de Medicina Santiago Ramón y Cajal, el botánico Blas Lázaro Ibiza y el físico Ignacio González Martí, todos ellos profesores vinculados a la universidad madrileña e igualmente a la Institución Libre de Enseñanza. Se desplazaron hasta la villa de Cangas animados por el médico local Ambrosio Rodríguez, muy amigo de Ramón y Cajal. Según publica El Distrito Cangués, el 22 de agosto de 1914, Eduardo Hernández Pacheco había comenzado

8 En estos estudios científicos de carácter naturalista es común la atención a determinados aspectos sociales como el modo de ocupación y explotación del territorio. Se observará un siglo más tarde en la Reseña físico-geológica del valle de Laceana. Provincia de León de Ángel Rubio, publicada en Madrid en 1954: «donde no es posible otra clase de cultivo, se cosecha, sin embargo, bastante yerba de superior calidad». 
ese mismo año la excavación arqueológica de la Cueva de la Paloma, en Soto de Regueras, y estaba buscando más cuevas por el interior de Asturias con restos de presencia humana, cuestión en la que no parece tener éxito en este recorrido aunque si aprovecha para realizar otro tipo de observaciones tal como queda constancia en el Boletín de la Real Sociedad de Historia Natural, donde se informa acerca de «[...] señales de glaciarismo en la región del puerto y laguna de Leitariegos [...]» (Hernández-Pacheco, 1914).

Algunos años más tarde, avanzada la siguiente década, será su propio hijo, Francisco Hernández-Pacheco, quien recorre las laderas de este macizo montañoso. Como resultado de esta experiencia incluye en la publicación periódica de la Sociedad de Historia Natural una nota titulada «Datos de Geología Asturiana (Leitariegos y Somiedo)» en la que se refiere a la estructura geológica y a la composición litológica, mencionando el origen glaciar de la laguna de Arbás y advirtiendo de la existencia de fósiles (Hernández-Pacheco, 1929).

Precisamente, en el mismo número del Boletín... R. Stickel, profesor auxiliar de la Universidad de Bonn, publica sus «Observaciones de morfología glaciar en el NO. de España» y describe las formas glaciares reconocidas al pie del pico de Arbas. Se trata de observaciones enmarcadas en un viaje realizado en agosto y septiembre de 1928 por la montaña del Noroeste peninsular con el objetivo de reconocer las principales manifestaciones glaciares cuaternarias (Stickel, 1929). Dedica un apartado entero al «Pico Cueto de Arbas. -Puerto y valle del arroyo de Leitariegos», encabezado con una descripción parcial de la silueta del Cueto en la que aparece, como en autores anteriores, la percepción del contraste entre la pendiente de la pared y la culminación:

«[...] se alza una abrupta pared, formada por areniscas grises de estratificación vertical y terminada por la cumbre plana del Cueto de Arbas [...]» (Stickel, 1929).

A continuación se ocupa de la morfología glaciar:

«En la pared que mira a NE. se han labrado dos circos, de los cuales el más al N. bajo la cumbre del Cueto, es el mayor. En el fondo de este circo se ve un número grande de montones de bloques erráticos, que muestran el extremo inferior del glaciar de circo que allí existió, situado de unos 1.600 a 1.640 m, de altitud. El otro circo está a unos 100 m. más arriba de un lago pequeño, bastante enrunado, de $1.755 \mathrm{~m}$. de altitud [...]» (Stickel, 1929).

La descripción da cuenta de la extensión del glaciar cuaternario y explica la forma del terreno que «acuna» la laguna.

«Este lago llena una hoya situada entre el muro de arenisca y el reborde de pizarras que está delante (lám. XXIV, fig. 2). El glaciar salía del circo y ha excavado la hoya del lago actual. Sus morrenas laterales están sobre la vertiente del reborde de la hoya lacustre que mira al puerto de Leitariegos, al cual no alcanza, sino que queda a una altitud de unos 1.600m. [...]» (Stickel, 1929).

Se subrayan, por tanto, otros elementos habituales en la consideración patrimonial de la montaña: la concavidad de las formas de relieve en roca desnuda esculpida por el hielo; y, como testigo contemporáneo de la acción glaciar, la presencia de la laguna (véase Figura 3). 


\section{Figuras 3 y 4}

A LA IZQUIERDA, LA LAGUNA SITUADAAL PIE DEL CUETO ARBÁS, A UNOS 1.755M DE ALTITUD SEGÚN STICKEL, EN UNA FOTOGRAFÍA TOMADA DESDE EL SUR POR EL PROFESOR ALEMÁN (INCLUIDA EN STICKEL, 1929). A LA DERECHA, LA LAGUNA OBSERVADA DESDE EL FLANCO SEPTENTRIONAL DURANTE LA VISITA DE FRANCISCO HERNÁNDEZ-PACHECO, EN UNA FOTOGRAFÍA DEL ARCHIVO DEL MUSEO NACIONAL DE CIENCIAS NATURALES
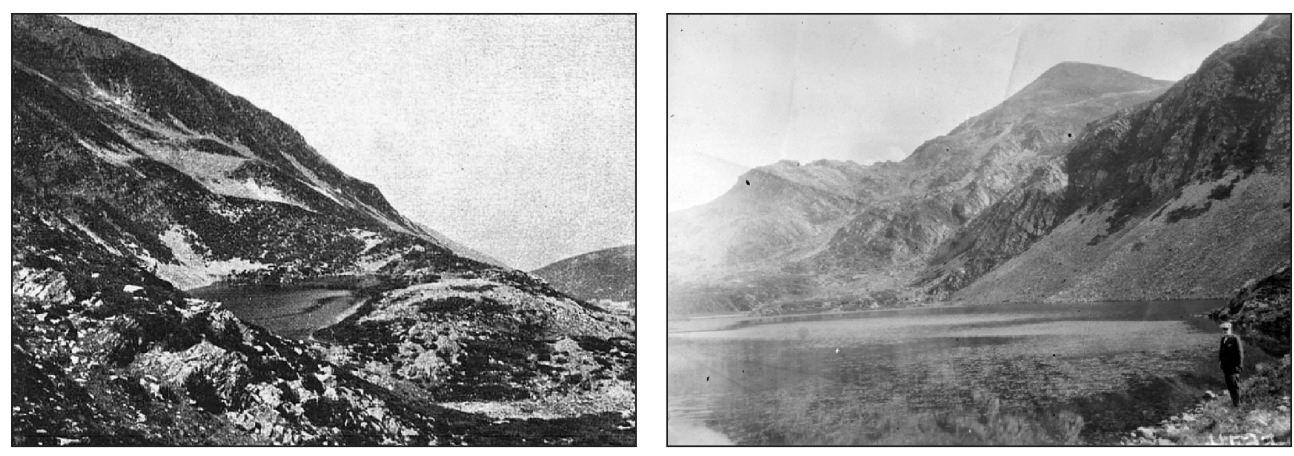

\section{III.3. El paisaje de Leitariegos en la institucionalización del excursionismo}

El interés levantado por el progreso científico que emana del reconocimiento de la montaña continental, junto a la difusión del ideal de exploración de sectores poco visitados y muchas veces percibidos como inaccesibles, supone un estímulo para la creación de clubes de montaña y asociaciones excursionistas a partir de la segunda mitad del siglo XIX. Muchos de ellos desarrollan cualidades de sociedades geográficas y culturales desde el momento en que sus miembros se esfuerzan en contrastar, completar y enriquecer la información disponible sobre cada macizo montañoso visitado (Schrader, 1879). Son portadores de modernas prácticas de montaña, pero también de una mayor preocupación por la conservación de la naturaleza (Debarbieux, 2008). Además, se encargan de la publicación periódica de boletines que se convierten pronto en una fuente documental y bibliográfica de primer orden: incluyen valiosos relatos de excursiones con información orográfica, geológica, toponímica, etnográfica, etc. y todo tipo de representaciones gráficas (dibujos, fotografías, mapas...), contribuyendo a la valoración de los elementos naturales y rurales de la montaña (Castañón y Frochoso, 2007; Saule-Sorbé, 2007).

Uno de los ejemplos más tempranos y significativos de este tipo de entidad con actividad en la montaña occidental astur-leonesa es la Real Sociedad Española de Alpinismo Peñalara. Se trata de una entidad madrileña creada en 1913 por un grupo heterogéneo de profesionales (astrónomos, literatos, profesores, funcionarios de la Administración Pública...) apasionados por la montaña e interesados en la práctica del alpinismo y de los deportes de nieve. Se trata, además, de un grupo influido por la Institución Libre de Enseñanza, en lo que respecta al desarrollo de actividad excursionista con fines pedagógicos (Mollá, 2010). Las informaciones llegadas de otros clubes y de iniciativas individuales animan a sus miembros a conocer todas las cordilleras españolas. Y en este contexto se enmarca la incursión «Por la montaña cantábrico-astúrica: desde Oviedo al Puerto de Leitariegos» que Arno Teichman realiza en el invierno de 1926.

Teichman reserva la jornada del 8 de enero para la subida al puerto y se sirve de la «línea de autos» de D. Segundino Cosmen, no perdiendo detalle del trazado de la carretera ni del aspecto 
del valle. Como es común en este tipo de textos, se mencionan las dificultades del camino -en este caso la pendiente y la sinuosidad-y los parajes que se divisan a medida que se completa el ascenso. Antes de alcanzar el puerto, la vista se coloca ya sobre el Cueto de Arbas, «que parece cerrar el valle» (Teichman, 1926). El Cueto permanece como lugar de referencia en la retina del visitante. En Leitariegos, como en tantos macizos de la cordillera y también pirenaicos, parece dibujarse una imagen patrimonial dominada por la imponente presencia de una montaña dominante.

Una vez iniciada la exploración a pie del puerto, algunos efectos lumínicos sorprenden al excursionista: «el majestuoso Cueto de Arbas» con «neveros helados brillaba en el sol matutino» (Teichman, 1926). De nuevo llama la atención la forma voluminosa del pico y la presencia de nieve que se acumula en altura y matiza la apariencia de aquél.

El autor repara en la dureza de la nieve en el inicio de su ascenso a pie. La apreciación del agua en diferentes estados es común en las publicaciones de este tipo. Y, en este caso, observada la laguna completamente helada, se pone en relación con las posibilidades que ofrece al deporte invernal (cuya aceptación despega entonces en España): «hubiera sido una pista incomparable para los deportes» (Teichman, 1926).

Durante la marcha hacia la cumbre del Cueto se acentúa la pendiente y, en consecuencia, la subida es «penosa hasta llegar a la cresta, por lo muy helada que estaba» (Teichman, 1926). La ingratitud de la marcha por la verticalidad y las condiciones del suelo, tan contrarias a las comodidades cotidianas que busca la sociedad del momento, no dejan de revestir interés para el excursionista. Brota la expresión de esa singular «moral del esfuerzo y la soledad» propia del imaginario de la montaña fraguado en nuestra sociedad contemporánea (Barthes, 1957).

El esfuerzo se compensa finalmente con el amplísimo panorama que ofrece la cima de la montaña: «es para verlo y no describirlo» dice Teichman. La emoción impregna el relato y revela una cierta herencia romántica en el movimiento excursionista. Como en el pirineísmo francés, los primeros grupos de montaña españoles asocian el conocimiento y el «sentimiento de la montaña» en sus prácticas (Martínez de Pisón y Álvaro, 2002). La percepción sensorial alcanzada en la cima remata, por tanto, la renovación de cuerpo y espíritu que proporciona la subida. La montaña, fuente de salud física y moral (Bozonnet, 1992), recompensa al afanado excursionista con la sensación de energía y poder que ofrece el vasto panorama divisado. Destacan entonces el límpido cielo («la atmósfera era tan transparente que se podía ver muy lejos»), la nieve («por [todos] lados montañas con sus cumbres nevadas») y la roca («un circo incomparable») (Teichman, 1926).

La Revista Ilustrada de Alpinismo Peñalara, que publica el relato de Arno Teichman, presenta cuatro años más tarde la experiencia ya mencionada del naturalista Francisco Hernández-Pacheco, también miembro destacado de la sociedad excursionista. Francisco Hernández-Pacheco elige el mes de agosto y se acompaña de su esposa, con quien toma la célebre línea de autos que asciende al puerto. Sus observaciones, recogidas en «Por los puertos de la cordillera cántabro-astúrica: de Leitariegos a Somiedo y los lagos», presentan elementos en común con las de Teichman (véase Figura 5). En la primera impresión ya aparece la figura imponente del Cueto:

«El Cueto de Arbas se levanta majestuoso frente a nosotros y a su pie apacible y en el mismo collado del puerto se agrupan las casas de Leitariegos [...]» (Hernández-Pacheco, 1930). 


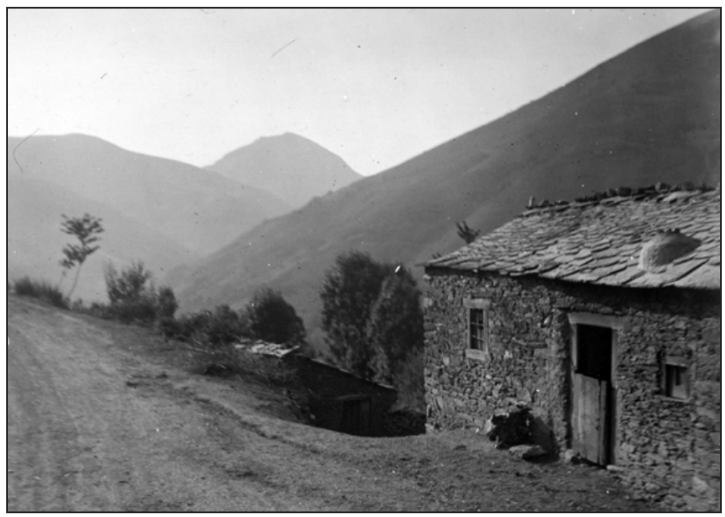

Además, al igual que otros visitantes en siglos anteriores, Hernández-Pacheco asocia la imagen de la mole montañosa y, en su base, del lugar habitado del puerto como representación básica del lugar. Así lo presenta en algunas de las fotografías publicadas (véase Figura 6).

El texto recoge ya de modo explícito la metáfora que, de algún modo, se anuncia en la obra de intelectuales precedentes: el Cueto es centinela del puerto. Por lo demás, continúa el interés por el estado atmosférico y los efectos de luz que matizan la percepción de las abruptas laderas. En este caso subrayan la huella del glaciarismo cuaternario, concretamente las morrenas y el circo:

«A nuestra espalda y tras el grupito de casas, se levanta majestuoso el Cueto de Arbas, el guardián del puerto que, curioso, se asoma por encima de las montañas astures, hacia las vallonadas leonesas. El sol, iluminándole lateralmente, deja ver en sus ásperas laderas la acción de los hielos cuaternarios, destacando netamente los lomos morrénicos al pie del pequeño circo que enmarca la laguna [...]» (Hernández-Pacheco, 1930).

Hernández-Pacheco y su acompañante suben igualmente a la laguna y al Cueto (véase Figura 9). Alcanzan la cima de éste y disfrutan de la vista, como ya lo hacía Teichman. El Cueto de Arbas se erige en privilegiado mirador natural:

«A nuestros pies, hundidos y umbrosos, se extienden los valles recorridos por la mañana; un poco más hacia el Este el Lago del Puerto, cuyas aguas duermen, y más allá el grupito de casas de Leitariegos, que comienzan a humear. Hacia el S. en la lejanía, se distinguen, difuminadas, las llanuras de El Bierzo, limitadas por sierras que sólo se adivinan [...]» (Hernández-Pacheco, 1930). 
Verticalidad en la montaña, surco y sombra en el valle, la calma en el entorno de la laguna y una señal del lugar habitado en el puerto: se dibuja una imagen que viene a enriquecer la «genealogía» de representaciones de Leitariegos, de este pintoresco lugar de pequeñas callejas y rincones rodeados de hórreos y casas con cubierta de ramaje o de pizarra (véanse Figuras 7 y 8), integrado en su marco de pastos de altura.

Figuras 6,7 y 8

EL PUEBLO DE LEITARIEGOS, INCLUYENDO ASPECTOS DE LAACTIVIDAD GANADERA Y

DE LAARQUITECTURA TRADICIONAL. EN LA IMAGEN INFERIOR SE OBSERVA EL EMPLAZAMIENTO AL PIE DEL MACIZO DEL CUETO ARBÁS. FOTOGRAFÍAS DE FRANCISCO HERNÁNDEZ-PACHECO, EN EL ARCHIVO DEL MUSEO NACIONAL DE CIENCIAS NATURALES.
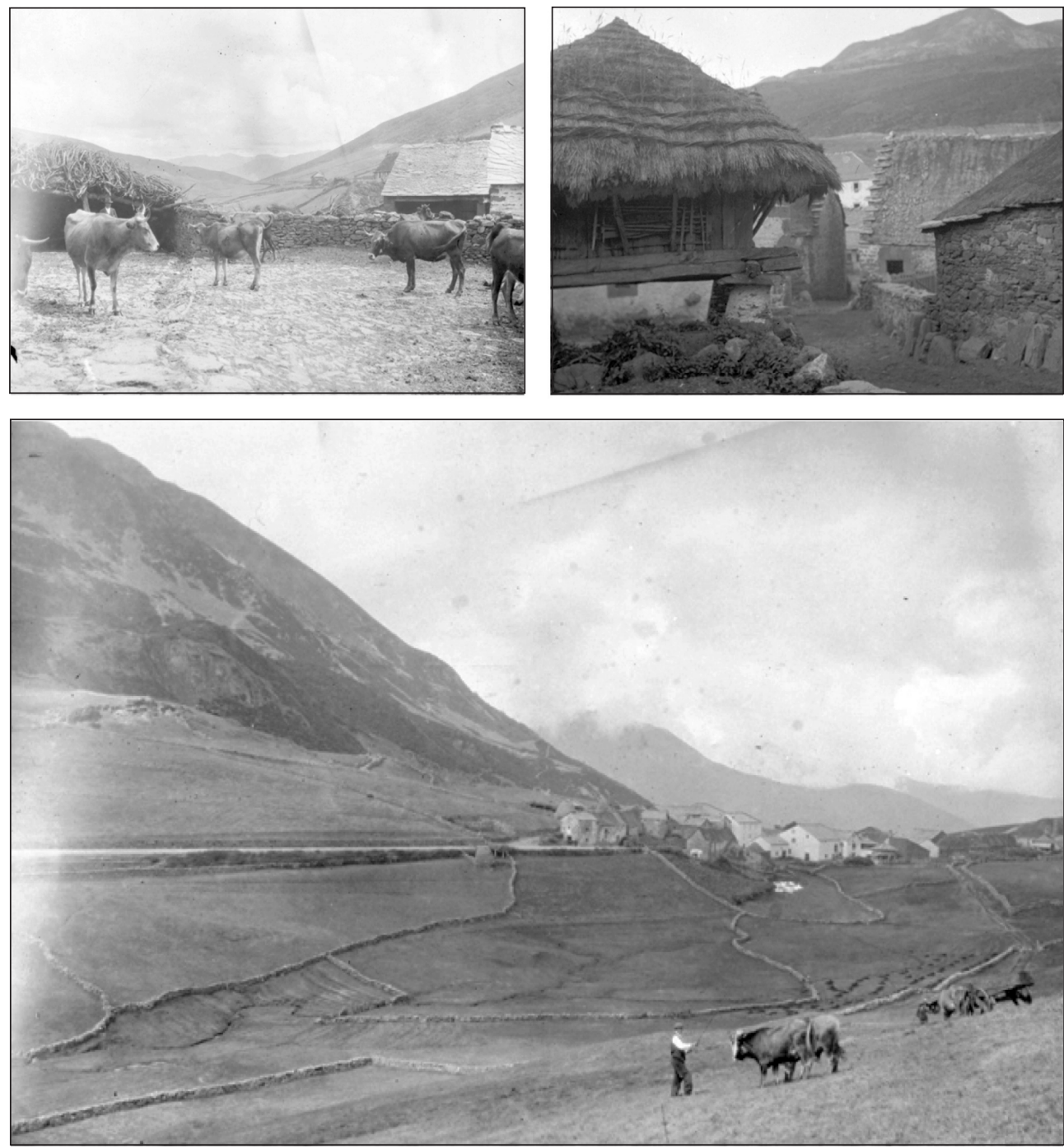

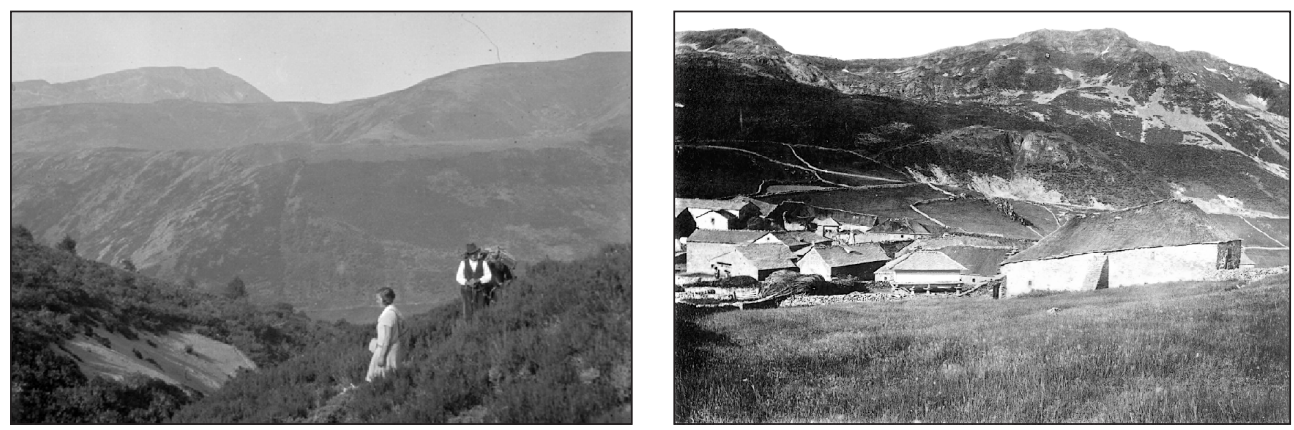

(Fuente: Rodríguez, 1900).

\section{III.4. Aspectos antrópicos del puerto en los estudios sociales y humanísticos}

La montaña de Leitariegos ha merecido también una atención notable de las disciplinas dedicadas al estudio de los hechos sociales, que ganan importancia al avanzar la Edad Contemporánea a medida que profundizan en sus campos de estudio. No sólo les favorece el desarrollo del aparato científico y estadístico de los Estados o la proliferación de centros universitarios. La creación de sociedades privadas preocupadas por la difusión del conocimiento histórico, geográfico, económico, sociológico, etnográfico, lingüístico, etc. y la iniciativa editorial para la difusión del conocimiento de la cultura y del patrimonio regionales contribuyen a la consolidación de los saberes sociales y humanísticos; lo que comprende nuevas aportaciones de la mirada intelectual a la montaña, como demuestra la obra Asturias: $\mathrm{Su}$ historia y monumentos. -Bellezas y recuerdos. Costumbres y tradiciones. -El bable. Asturianos ilustres. Agricultura e industria. -Estadística de Octavio Bellmunt, médico y empresario de artes gráficas, y Fermín Canella, periodista y profesor de la Universidad de Oviedo. Fue publicada entre 1895 y 1900 , en sucesivas entregas, hasta completar tres tomos. Y en el tercero se incluye parte de la monografía que José Rodríguez Riesco escribió para el concejo de Leitariegos ${ }^{9}$, entonces independiente del de Cangas del Narcea y con blasón distintivo que incorpora la imagen de sus distintivas montañas «bajo la cruz asturiana y el león del sello de su real favorecedor Alfonso XI» (Rodríguez, 1900) ${ }^{10}$.

9 Faustino Meléndez de Árvas escribe en la misma obra de Bellmunt y Canella el capítulo dedicado a Cangas de Tineo, destacando en él la riqueza forestal de la zona y reclamando la protección oficial del Estado español como Estados Unidos lo había hecho de Yellowstone en tiempo reciente. Se trata de una de las primeras voces que reivindican para un sector de la montaña cantábrica su declaración como espacio natural protegido. No obstante, Meléndez de Árvas no se refiere en concreto a Leitariegos, entonces con concejo independiente, pero sí a territorios que un siglo más tarde compartirán con el puerto la figura de Parque Natural, entre ellos los de las fuentes del Narcea (Meléndez, 1897).

10 El texto completo de Rodríguez Riesco ha sido dado a conocer en un estudio reciente de Juaco López Álvarez, Director del Museo del Pueblo de Asturias, con prólogo del empresario del sector lácteo Francisco 
Rodríguez Riesco, Secretario del Juzgado de Leitariegos y secretario municipal, escribe una reseña descriptiva e histórica con abundante información geográfica. Sobre la huella antrópica, Rodríguez Riesco aporta algunas notas que tienen que ver con los aprovechamientos agrarios y la caza, venida a menos esta última. Y, por supuesto, aparece en el texto el condicionante de la nieve para la economía y la vida de los habitantes del puerto, una vez más destacada como elemento definitorio del paisaje durante buena parte del año:

«Los pastos de estas alturas son ricos y abundantes; pero desde fines de Septiembre á Junio los cubre la nieve, que baja hasta los pueblos haciendo penosa y difícil la vida. De aquellas cumbres de intrincadas selvas huyeron osos y lobos, jabalíes, rebecos y corzos, faisanes y perdices, aunque de estas aves aún quedan señales, como recuerdo de aquella variada y numerosa caza [...]» (Rodríguez, 1900).

Luego se refiere al poblamiento, indicando qué localidades componen el concejo (ofrece fotografías de Brañas de Arriba y Leitariegos, realizadas -al menos la del puerto, véase Figura 10- por Octavio Bellmunt) y qué tipo de vivienda se encuentra -con pozo en su interior debido al encierro invernal-. Alude, además, a los principales oficios de sus habitantes: la histórica arriería y la ganadería de vacuno mantenida según el sistema tradicional, con estabulación en la época de peores condiciones de tiempo y pastos de altura en verano. También están en el texto la hospitalidad y los servicios de ayuda y orientación por parte de los pobladores de Leitariegos a quienes utilizaban los caminos en época preindustrial:

«Mucho más antes, pero también ahora, los vecinos eran en su mayoría arrieros de coleto, recorriendo dilatadas comarcas al lado de sus reatas de buenas muías y al compás del monótono son de esquilas y cencerros. Los otros moradores dedícanse casi todos á la ganadería vacuna, estabulada dentro de cabañas ó chozas, en los muchos meses del largo invierno, [...]. En el verano pasan las vacadas á los ricos pastos de las alturas.

Los antiguos caminos eran poco menos que sendas ó estrecha vía cubiertos por sobrepuestas capas de nieve en los dichos meses invernales, haciendo difícil, sino imposible, la circulación de pastores y pasajeros, á cuyo amparo y guía, corriendo mil peligros, salían los vecinos haciendo señales á los perdidos caminantes con fogatas y sones de campana.[...] Contando con tales inconvenientes, son las viviendas humildes y bajas, con techumbre de paja y de figura cónica; todas están habilitadas de pozo para aquella temporada de reclusión y de incomunicación

\footnotetext{
Rodríguez (presidente de ILAS-Reny Picot y nacido en Trascastro). El propio empresario realiza una interpretación de los valores del Puerto y de sus habitantes basada en su experiencia de vida y tránsito por aquellos parajes "de una zona sin par, limítrofe con León, y cuyos montes están entre los más escarpados y feraces de la Cornisa Cantábrica" (Rodríguez, 2015). En cuanto al trabajo de Juaco López, viene a completar con acierto la información disponible acerca del encargo de Octavio Bellmunt a José Rodríguez Riesco. López analiza las características del texto original, que no fue publicado íntegramente sino resumido debido a algunos problemas económicos con que contó la edición. Ofrece también una serie fotográfica de interés por mostrar aspectos históricos y actuales de los territorios estudiados, incluyendo algunas de la Colección del Museo del Pueblo de Asturias realizadas por José Ramón Lueje y Fritz Krüger (López, 2015).
} 
desde Septiembre á Mayo, en que las gentes se encierran con sus provisiones, á fin de poder subsistir cuando no es posible la salida [...]» (Rodríguez, 1900).

Otros aspectos etnográficos de interés aparecen en el texto que escribe Luis Bello, jurista, ensayista y político, durante un largo itinerario que le lleva a conocer las escuelas del cuadrante noroccidental español. Considerado miembro de la Generación del 98, Bello comparte con ésta, entre otros rasgos intelectuales, la actividad viajera (Rojo, 1979-80), en la misma línea que la Institución Libre de Enseñanza promueve entre científicos sociales y humanistas desde bien avanzado el siglo XIX. Los recorridos por León y Asturias, junto a otros efectuados por los alrededores de Madrid, incluida la sierra, y Castilla, tienen lugar en los primeros meses de 1922, poco antes de que vean la luz los artículos correspondientes en El Sol (Rojo, 1979-80). Éstos se incorporan cuatro años más tarde al primero de cinco volúmenes de un trabajo recopilatorio titulado Viaje por la Escuelas de España, encontrándose en el capítulo «Viaje por Asturias» el texto que nos interesa:

«Por el claro abierto entre dos lomas desmesuradas, leonesas todavía, penetran las primeras nieblas de Asturias. El viento y el sol las rechazan, deshilachándolas. Tardan mucho en fundirse. A veces estas neblinas se desploman Castilla adentro. Sin embargo, suelen quedarse en su hoya, remansadas, y hoy es uno de estos días felices en que se duermen en el umbral y se pegan al monte como si incubaran la primavera. Entro, pues, en Asturias, por el Puerto de Leitariegos, libre de nieve y con buen sol. Otros años, en Marzo y Abril, la campa -grande, desolada, de hierba pobre, sin árboles, como toda meseta de las cumbres- está cubierta por muchos palmos de nieve y apenas sobresales las columnas -catalejos de piedra- que sirven para delatar el camino [...]» (Bello, 1926).

El fuerte contraste advertido entre tipos de tiempo atmosférico frecuentes en una y otra vertiente, tan característico y llamativo en cualquier de cualquier paso de la divisoria, introduce un relato de sumo interés por su caracterización del paisaje. De la campa del puerto Bello señala una imagen pobre, distinta de aquellas anteriores que incidían en la riqueza de los pastos. Pero el autor sí menciona, como otros autores, la abundante presencia de nieve que oculta el camino. Luego el paisaje torna en espectáculo ante una mirada deslumbrada: la amplitud y profundidad del precipicio que corona esta parte alta del valle, de montes sombríos parcialmente cubiertos por la niebla; el aspecto de las aldeas rodeadas de bosque, pradería y ganado, y colgadas de las empinadas pendientes por las que la carretera serpentea; o el pintoresquismo de las cubiertas cónicas de las viviendas en Brañas de Arriba, que, por sus materiales y singularidad formal, recuerdan, según Luis Bello, a construcciones africanas. Encontramos, por tanto, una evocación de lo exótico al tiempo que una comparación con rasgos etnográficos extra-continentales:

«Entrar en Asturias por Leitariegos es asomarse a uno de los grandes y magníficos espectáculos que puede ofrecer al hombre la montaña. [...]Solamente unas cuantas casas de camino real. Y, sobre todo, el camino, el puerto, que ya basta, pues sólo con un kilómetros empezamos el descenso por la vertiente de las Brañas, y 
éste es el lugar más hermoso que he visto y pienso ver en mi vida. Será porque la niebla suaviza un poco el tono sombrío de los montes que le sirven de fondo. Será porque todo el primer término está iluminado por una luz intensa, cálida; y en este inmenso derrumbadero, que la carretera baja en zig-zag, pueblos, bosques, prados y ganados que en ellos pastan, aparecen como en tangente, sostenidos por arte mágico. [...] El primer pueblo que ha logrado trepar hasta aquí se llama Brañas de Arriba, y se afirma como puede, agarrándose al suelo con los machones de sus hórreos y ofreciendo a la nieve unos extraños techos cónicos, africanos, de bálago o de paja hábilmente trabada por unas varas que sirven de flejes [...]» (Bello, 1926).

Estos rasgos singulares llaman también la atención de Fritz Krüger, lingüista y etnógrafo alemán de la Universidad de Hamburgo, que viajó en compañía de su mujer por el suroeste de Asturias con la intención de llevar a cabo un estudio etnográfico de los concejos de Ibias, Degaña y Cangas del Narcea. En la obra de Krüger, esencial para acercarse al modo de vida tradicional de los habitantes de este territorio, se desliza, en primer lugar, una de las más frecuente representaciones contemporáneas de las comarcas montanas al hacer alusión a la inaccesibilidad del suroccidente asturiano, motivada, sin duda, por la orografía, que dificulta la expansión de la red de carreteras y explica el mantenimiento de los modos de vida por lo que se interesa y se siente atraído:

«Esta parte de Asturias está unida al mundo exterior por una carretera que desde Oviedo conduce a la provincia de León, pasando por Tineo, Cangas de Narcea y el puerto de Leitariegos $\left(1.301 \mathrm{~m} .{ }^{11}\right.$. La economía y la vida de esta región han permanecido completamente arcaicas, lo que es perfectamente comprensible dado el carácter grandemente quebrado y montañoso de la región, dadas sus escarpadas vertientes, en las que están situados los pequeños poblados de pastores y campesinos, y el débil nudo de comunicaciones (pues, aparte de la citada carretera, solamente existen caminos para carros y peatones) [...]» (Krüger, 1948).

Estas impresiones de aislamiento, arcaísmo o singularidad perviven aún varias décadas, como demuestra el historiador de la Universidad de Oviedo Juan Ignacio Ruiz de la Peña, al que nos hemos referido anteriormente. En el mismo artículo «El coto de Leitariegos. Una comunidad de montaña en la Asturias Medieval» ofrece una aproximación geográfica que resulta, en parte, de una excursión realizada en compañía de Arturo Rodríguez ÁlvarezBuylla y el también historiador Eloy Benito Ruano en el otoño de 1972:

«La carretera [...] introduce al viajero en una de las comarcas más apartadas, arcaizantes y de mayores atractivos etnográficos y turísticos entre las muchas que, todavía hoy, pueden encontrarse en la región asturiana [...].

11 Aún en tiempo reciente han continuado las inexactitudes relacionadas con los datos de altitud. El puerto de Leitariegos se encuentra a 1.525 metros de altitud sobre el nivel del mar. 
Hemos rebasado los $1.000 \mathrm{~ms}$. de altitud y respiramos ya el aire delgado y puro de nuestros puertos. En la ladera de la derecha se ofrece a la mirada curiosa del viajero un espectáculo de insólita belleza: el que brindan los caseríos de Brañas de Abajo y Brañas de Arriba, distantes entre sí unos centenares de metros» (Ruiz de la Peña, 1979).

El relato, de elevada sensibilidad, se carga de fascinación ante el aspecto de las aldeas, como percibimos en otros humanistas, puesta la mirada en los caseríos de Brañas de Arriba y Brañas de Abajo, en la impresión de apacibilidad y, casi, atemporalidad, en la peculiaridad del antiguo caserío de mampostería, con planta circular, y cubierta cónica de paja:

«Un silencio profundo flota en el ambiente; apenas dos hogares humean: aquí se ha detenido el tiempo. Recorremos las angostas callejuelas de Las Brañas, con sus casas elementalísimas de planta circular o elíptica y recias paredes de mampostería sobre las que descansa una empinada techumbre cónica de paja. Nos encontramos ante una de las escasas supervivencias que quedan de un sencillo y primitivo tipo de construcción circular -el de la pallaza- que tuvo amplia difusión desde tiempos remotos por el Noroeste de la Península [...]» (Ruiz de la Peña, 1979).

La aproximación de Ruiz de la Peña concluye subrayando los rasgos históricos y geográficos definitorios del puerto:

«Presidido por la ermita de San Juan, el pequeño caserío del Puerto -otrora cuna de legendarios arrieros de coleto- se apiña a ambos lados de la ruta; estamos en el pueblo más alto de Asturias: $1.525 \mathrm{~ms}$. El viajero encontrará aquí la misma cordial acogida que ya brindaban los antiguos hospitaleros del Puerto a los peregrinos y caminantes de hace ochocientos años. Pasado el poblado se extienden las llanas y jugosas praderías de Leitariegos -blancas de nieve en la larga y rigurosa estación invernal- flanqueadas, a la derecha, por la majestuosa mole calcárea del Cueto de Arbas: 2.000 ms. de altitud» (Ruiz de la Peña, 1979).

\section{HACIA LA PRIMERA ACCIÓN OFICIAL CONTEMPORÁNEA}

Las caracterizaciones y representaciones debidas a tan diversos actores intelectuales vienen a componer una imagen patrimonial perceptible en la puesta en valor actual del puerto de Leitariegos y del macizo montañoso del Cueto Arbás. Pero no todas tienen el mismo efecto en el camino a la primera acción oficial de valorización. La percepción de la nieve como elemento inherente a la vida en este lugar por las dificultades que ofrecía a la vida y al tránsito en una ruta transmontana fundamental, y por motivar una dedicación asistencial que originaría su privilegio real y la permanencia del pueblo, adquiere una nueva dimensión en las décadas centrales del siglo XX. La abundancia de nieve, que sepulta caminos, campos y montes durante buena parte del año, comienza a concebirse como fuente de ocio, y a la postre fuente de riqueza, al observarse óptima para la recreación en montaña y, particularmente, para el deporte de nieve. 
Un año antes de que Teichman se refiriera en la Revista Peñalara a las posibilidades que las inmediaciones del puerto y del Cueto ofrecían a la práctica deportiva, aparecía en el diario La Voz, de Madrid, una crónica de Ramón García Redruello, juez de primera instancia en Cangas del Narcea en los años 1924 y 1925, en la que recomendaba a la misma Sociedad Peñalara, entre otras formaciones excursionistas, la visita a Leitariegos por responder a las características de los lugares frecuentados en sus excursiones colectivas. García Redruello considera esta zona un «paraje adecuado para el alpinismo» y lamenta el desconocimiento que del mismo tienen los aficionados al deporte de invierno. Además, señala el mismo paralelismo con la sierra madrileña que evocan Rivas Goday y Rivas Martínez (1959) al referirse a «su interesante laguna, que recuerda mucho la grande de Peñalara, en el Guadarrama». Y menciona un artículo suyo publicado en la revista Vida Leonesa, de la Sociedad Cultural Deportiva de León, en el que anima a aprovechar los puertos de Pajares y Leitariegos como centros alpinos (García, 1925; López, s.f. b).

Al mismo tiempo, no deja de difundirse el excursionismo de visitantes foráneos o de población local y regional, como demuestran las noticias del Boletín del Tous pa Tous La Maniega, de la Sociedad Canguesa de Amigos del País, que dejan constancia de iniciativas de diversos grupos para disfrutar «lo indecible ante aquellos soberbios paisajes», quedar «admirados de lo grandioso y fuerte de todo aquel incomparable paisaje» o «pasar unos días acampados al pie de la laguna del Puerto de Leitariegos» (La Maniega, 1930, 1931a y 1931b). Del gozo debido a la contemplación del mismo paisaje nos ofrece esta publicación periódica local un curioso testimonio en forma de poema, firmado por Barrena en Buenos Aires en junio de 1928. En sus versos, dedicados «Al Cueto de Arbas» permanece la idea de

$$
\begin{array}{r}
\ll[\ldots] \text { enorme mole, que subes } \\
\text { por entre las brañas del monte. } \\
{[\ldots . . \text { eres rey de las montañas, }} \\
\text { el que cobijas a Brañas } \\
\text { y el que refugias al Puerto. } \\
\text { Pico de aspecto imponente, } \\
\text { tu silueta es cual ninguna, } \\
\text { y en tu cima es sorprendente } \\
\text { admirar la permanente } \\
\text { y salitrosa laguna [...]» } \\
\text { (La Maniega, 1928). }
\end{array}
$$

Las excursiones al puerto y a la laguna con una intención recreativa, sobre todo de iniciativa local, se mantendrán en años sucesivos, como evidencian los artículos de otra revista preocupada por atender la crónica comarcal: Narcea, Órgano del Club Narcea, de ambiente asturiano, editada en Madrid (Narcea, 1935).

Respecto a la práctica del esquí en Leitariegos, puede documentarse con cierta precisión en la década de 1950. Según testimonios recogidos por Evencio Asenjo, profesor de esquí en Leitariegos, algunos militares y aficionados experimentados en otras cordilleras contribuyeron a difundir la técnica y nuevos materiales que fueron sustituyendo a aquellos rudimentarios habituales en el lugar (Asenjo, s.f.). La prensa leonesa recoge en esos años movimientos 
de distintas entidades deportivas que se desplazan a la montaña de Leitariegos para practicar deportes de nieve, entre ellas la Sociedad Deportiva Hispánica (Diario de León, 1958 y 1959). Y los cursos de esquí y algunos campeonatos en distintas modalidades se impulsan desde la provincia leonesa en la siguiente década aprovechando la colaboración de los Grupos de Montaña y Esquí de León del Frente de Juventudes, la Diputación de León, la Federación Española de Esquí, la Sociedad Deportiva Hispánica y el Ayuntamiento de Villablino, entre otras instituciones. Diferentes secciones de la Organización Juvenil Española (O.J.E.) y la sociedad Peña Rubia, con muchos socios del Bierzo y Laciana, se encuentran entre las entidades que fomentan el esquí en Leitariegos a través de cursos y campeonatos como el «Inter-valles», en el que participa igualmente la sección asturiana de Cangas del Narcea (Diario de León, 1963; Proa, 1968a y b). De hecho, el impulso del esquí en la vertiente asturiana se debe, en buena medida, a Manuel Pérez Frade, creador de la sección de la O.J.E. en Cangas del Narcea y Delegado Local de Juventudes en la misma localidad (Pérez, 1998; El Tousp@Tous, 2014).

En este contexto, se cede y habilita la casa dedicada al cobro de las antiguas tasas provinciales, que era propiedad de la Diputación de Oviedo y estaba en desuso, para convertirla en albergue juvenil de la O.J.E., tras la petición de la Delegación de Juventud Local y del ayuntamiento de Cangas del Narcea. Esta nueva instalación facilitó la celebración de actividades de montaña y cursillos, con los que la afición al esquí -al principio escasa en la comarca- se fue incrementando. Con todo, no existían medios de arrastre por lo que era necesaria la carga de esquís al hombro en el ascenso a la vertiente del macizo (Pérez, 1998). Por este motivo, la sociedad Peña Rubia, creada en la vertiente leonesa, se preocupará por recaudar fondos para el pago de un tele-arrastre en los inicios de la década siguiente, manifestándose asimismo a favor de la construcción de un albergue adecuado (Diario de León, 1970; Pérez, 1998).

Creada ya una Federación Astur-Leonesa y dado que el número de aficionados iba en aumento $^{12}$, con afluencia muy importante de Villablino y Ponferrada -donde la afición se había iniciado antes-, se empezó a plantear la posibilidad de poner en funcionamiento una estación de esquí (López, 1979; Pérez, 1998). Las autoridades ya consideran la promoción del puerto de Leitariegos como lugar de actividad turístico-deportiva, donde el paisaje, como en muchos centros de atracción turística, juega un papel importante pues su calidad, entre otros factores, atrae a los visitantes (Espejo, 2011). La primera Asamblea de los Centros de Iniciativas y Turismo de León, reunida en la primavera de 1970, reclama apoyos económicos para este espacio (Proa, 1970b). También se convocan reuniones interprovinciales, con representación de los ayuntamientos interesados y de las diputaciones, con el ánimo de constituir un Patronato y llegar a acuerdos de colaboración para las campañas de promoción. Surge entonces el proyecto de un refugio de montaña por encargo del Ayuntamiento de Villablino, que presenta su alcalde -y diputado provincial leonés- Manuel Barrio Valcárcel, figura clave en estas operaciones (Pérez, 1998; Proa, 1970c). Las diferentes administraciones locales y provinciales implicadas anuncian ayudas para este sector.

12 Una muestra de la afición creciente es el ciclo de cine deportivo organizado en el invierno de 1972 por la berciana Peña de Montañeros Catoute, también implicada en la promoción del esquí en las modalidades de descenso y marcha (Diario de León, 1972a). 


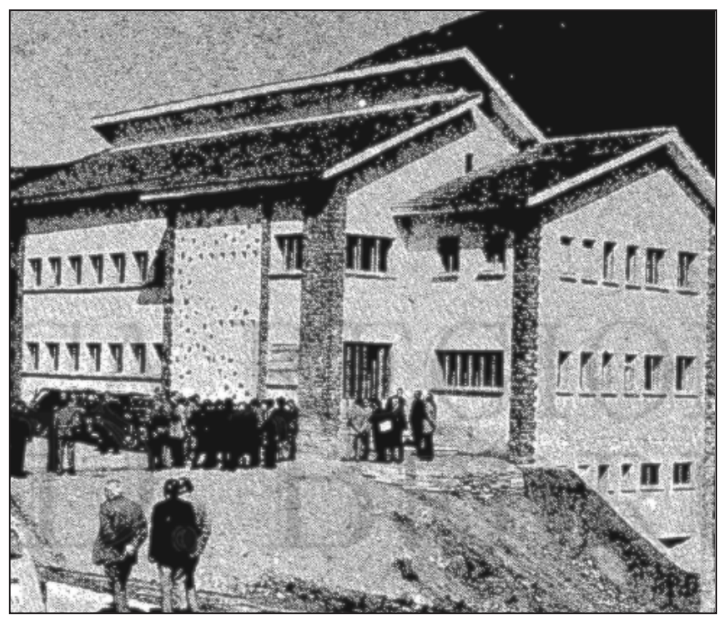

Las obras correspondientes al proyecto de tele-arrastre se inician finalmente en 1972, una vez que una Junta Gestora encabezada desde el Bierzo e impulsada por Peña Rubia, consigue el crédito necesario. Y el albergue promovido por el Ayuntamiento de Villablino, con apoyo de otras corporaciones como la de Palacios del Sil, la Delegación Nacional de Educación Física y Deportes y la Diputación de León, se inaugura en octubre de 1973 previa cesión a la Diputación leonesa (Diario de León, 1972b; Proa, 1973). Nos encontramos así en el germen de la estación invernal.

Observamos, por tanto, como en Leitariegos el proceso de patrimonializacion se consolida con una primera acción oficial que prioriza un sentido utilitario de la montaña distinto del agroganadero tradicional. El contexto político y económico del país, donde el turismo se erige en motor de desarrollo alternativo, explica que las autoridades locales y provinciales encuentren particularmente atractiva la explotación antes que la protección de este territorio; opción que fue posible debido a que este espacio no había recibido con anterioridad una atención destacada por parte de los organismos oficiales promotores de los primeros movimientos conservacionistas en España.

\section{EN LA CONSOLIDACIÓN DEL PROCESO DE PATRIMONIALIZACIÓN: ENTRE LA EXPLOTA- CIÓN Y LA PROTECCIÓN DE LOS RECURSOS}

De los componentes y valores que justifican el carácter excepcional de este lugar, es finalmente la abundancia y la persistencia de la nieve la que genera en primera instancia una atención oficial institucional decidida, aunque nunca deja de percibirse el interés de un excursionismo no estacional. El paisaje, ciertamente apreciado por la singularidad de los elementos naturales y rurales que lo componen, por su atractivo estético, ya difundido desde antiguo, por las sensaciones que despierta su contemplación, se concibe en este momento, 
sobre todo, como marco y soporte de una actividad deportiva y turística con demanda creciente en las comarcas circundantes; actividad que pone en juego la relación entre cuerpo, esfuerzo físico y espacio (Damery, 2004).

El paisaje está presente en esta valorización institucional pero no porque la preocupación de las autoridades se dirija en un primer momento a su conservación. Lo hace como objeto, por un lado, de admiración pero, también, de adecuación para la práctica deportiva. Y ello implica la introducción de medios técnicos, de modo que su atractivo, al tiempo que se ensalza, se modifica (Espejo, 2011). La nueva experiencia en la montaña resultante de estas acciones oficiales no supondrá en este caso una sumisión del individuo a la montaña sino, al contrario, de la montaña al individuo (Bozonnet, 1992). En efecto, la implantación de un nuevo uso asociado a la demanda de espacios de ocio en la naturaleza por los habitantes de zonas urbanas conlleva la incorporación de elementos que no se integran de manera armónica en el paisaje. Y aunque la estación crece en las siguientes décadas muy progresivamente, sin llegar a alcanzar una superficie muy amplia, su huella en el paisaje es muy visible entre el nivel del puerto y los dos mil metros de altitud (Sevilla y Rodríguez, 2015). En efecto, las pistas abiertas en la ladera y que han afectado a los depósitos morrénicos que la tapizaban, unido a la desaparición de la cubierta vegetal y, provocado por las actuaciones anteriores, el desencadenamiento de activos procesos de arroyada superficial, han dado lugar a una degradación significativa de este territorio. Junto a esa cuestión, la modificación del paisaje preexistente se ha completado con la instalación de remontes mecánicos, a lo que recientemente se ha unido la construcción de un pequeño embalse de abastecimiento para la innovación artificial y la habilitación de un aparcamiento de reducidas dimensiones junto a la carretera.

La estación de esquí se concibe como un recurso de ocio y económico para el occidente de las provincias de León y Asturias, donde la población no disfruta, por su posición de cierta marginalidad con respecto a las áreas más dinámicas de sus provincias y comunidades autónomas, de muchas más oportunidades. Pero ello no justifica la postura de ciertos colectivos y también defendida por determinadas administraciones, partidarios de la extensión del área esquiable. Actuar en este sentido supone acrecentar el deterioro de un espacio de montaña frágil e igualmente alterado por la demanda de recursos minerales (extracción de carbón) en la segunda mitad de la década de los ochenta y, por tanto, con anterioridad a las acciones de protección oficial ${ }^{13}$.

Más tarde, el conjunto de Leitariegos y el macizo del Cueto Arbás sí ha sido reconocido por los valores revelados más arriba, que han motivado su protección oficial. Con todo, tal como ya se ha advertido en el texto introductorio de este trabajo, el paisaje no es el valor principal y el argumento que constituye el motivo de protección. Sí subyace en la declaración de protección de estos espacios pero no se recoge más que parcialmente el complejo bagaje cultural acumulado históricamente (al que se hace referencia en los apartados II y III de este

13 Entre 1985 y 1989 se lleva a cabo la explotación del yacimiento de carbón ubicado en el puerto de Leitariegos a través del método de transferencia de estériles. El plan de explotación se acompañaba de un plan de restauración del espacio natural afectado por las labores mineras, resultando llamativa la escasa valoración que en ese documento se hace del territorio y el optimismo que preside el análisis de las consecuencias para el medio resultantes de la actividad que se proyecta. Así, la restauración del espacio afectado sería deficiente, observándose en la actualidad, a pesar de haberse repoblado el área con coníferas, activos procesos erosivos sobre las laderas aún sin colonizar de forma completa por la vegetación, situación que se ve agravada por la existencia en este sector de numerosas pistas forestales (Castaño, 1984; Redondo, 1988). 
artículo), atendiendo la Administración primordialmente a los valores ambientales y ecológicos (hábitats naturales, presencia de especies de animales singulares, aspectos biogeográficos relevantes...). El sector meridional de este conjunto montañoso, perteneciente administrativamente a la provincia de León, forma parte a su vez del valle de Laciana, espacio que está incluido dentro de la Zona de Especial Conservación (ZEC) "Alto Sil”, de la Zona de Especial Protección para las Aves (ZEPA) "Alto Sil" y del Espacio Natural "Sierra de Ancares". Desde 2003, el valle de Laciana es además Reserva de la Biosfera. Por su parte, el sector septentrional, perteneciente a la provincia de Asturias, es un espacio amparado igualmente bajo diferentes figuras de protección: Reserva Natural Parcial de Cueto de Arbas (incluida en el Plan de Ordenación de los Recursos Naturales de Asturias -PORNA- pero aún pendiente de declaración efectiva); Zona de Especial Conservación (ZEC) de Fuentes del Narcea, Degaña e Ibias; ZEPA de Fuentes del Narcea, Degaña e Ibias; Parque Natural de las Fuentes del Narcea, Degaña e Ibias y Reserva de la Biosfera del mismo parque.

Se añade a lo anterior que el complejo glaciar del Puerto de Leitariegos ha sido designado como Lugar de Interés Geológico (LIG 0-95) en el Catálogo del Patrimonio Geológico elaborado por el Instituto Geológico y Minero de España. Por otro lado, el Camín Real de Leitariegos, integrado desde hace dos décadas en el Programa de Caminos Naturales del Ministerio de Medio Ambiente y Medio Rural y Marino, se incluye en el Inventario de Patrimonio Cultural de Asturias en 2011, debido a su condición de vía histórica.

En lo que hace referencia a la valoración de los elementos naturales y del paisaje, en la declaración de las diferentes figuras de protección que afectan a este territorio se destacan, como ya se ha señalado, aquellos aspectos que tienen que ver con la importancia de los hábitats naturales, como por ejemplo las formaciones de turberas asociadas a los espacios lagunares o la vegetación de alta montaña constituida por matorrales de enebro, brecina y arándanos que se desarrolla por encima de los 1.800 metros de altitud en la alineación del Cueto Arbás. Junto a lo anterior, también se resalta la presencia en este territorio de especies faunísticas de gran relevancia como son el oso pardo cantábrico, el urogallo, el lobo y la nutria. Po otro lado, el reconocimiento de los valores naturales de este espacio también se refleja en la puesta en marcha de normativas específicas para garantizar la conservación de algunos de los elementos más amenazados, destacando los planes de recuperación del oso pardo y su consideración como corredor biológico del mismo.

En la declaración de la Reserva de la Biosfera de las Fuentes del Narcea, Degaña e Ibias se afirma que reúne las condiciones necesarias para cumplir los tres objetivos básicos de los territorios incluidos dentro de esta figura de protección, indicando que

"[...] posee un medio natural caracterizado por su gran diversidad y elevado grado de conservación y en su territorio se asientan comunidades locales cuyo desarrollo socioeconómico se está llevando a cabo de un modo compatible con la conservación de dichos valores, por lo que se constituye como un lugar privilegiado para el ensayo y demostración de modelos de desarrollo sostenible [...]" (Principado de Asturias, 2013).

Y en la Reserva de la Biosfera de Laciana se mencionan las cualidades paisajísticas, indicando que 
"[...] Los prados, huertos y pueblos del fondo de valle, los bosques mezclados con brezales y brañas en las laderas y las zonas de cumbres, frecuentemente cubiertas de nieve, con arandaneras, pastizales y roquedos, crean un mosaico de gran contraste cromático. Los matices del verde en verano, el contraste del blanco de las cumbres con los marrones del bosque en invierno y los tonos amarillentos y rojizos del otoño, espectacular aquí por la gran variedad de árboles, generan sensaciones inolvidables [...]" (Santos, s.f.).

En este proceso de patrimonialización, por otro lado, los habitantes toman conciencia de una identidad territorial marcada secularmente por hábitos y formas de vida y trabajo, condicionados éstos por el tipo de medio en el que viven (Béghain, 1998). Y esta identidad se encuentra asimismo en la base de la construcción de una imagen patrimonial de Leitariegos y su entorno. Así lo señala Fernández Salinas (2013) en su clasificación de los paisajes culturales de Asturias, al incluir este espacio en la categoría de "referentes geográficos connotados" y más concretamente en el tipo de zona de tránsito.

En relación con este aspecto de la patrimonialización de Leitariegos, la histórica asociación El Tous pa Tous, Sociedad Canguesa de Amantes del País ha venido realizado una importante labor de difusión del conocimiento en las últimas décadas a través de una intensa tarea de documentación y divulgación de textos y noticias históricas, geográficas, etnográficas, literarias, etc. Por su parte, el Grupo Ecologista Cangués Azor (GECA), fundado en Cangas del Narcea en mayo de 1985, se ha ocupado de la edición de guías didácticas sobre el río Narcea y el Camín Real. De su labor destaca un importante trabajo de campo para reconocer el trazado del camino original. Gracias a este tipo de iniciativas de asociaciones locales, los caminos naturales, fundamentales históricamente en el devenir del territorio atravesado, recuperan nuevamente cierto protagonismo en el desarrollo económico, ahora con un uso distinto ligado ahora al disfrute sosegado del paisaje.

La oportunidad originada por el reconocimiento institucional de este territorio y, especialmente su inclusión, tanto del área asturiana como de la leonesa, en redes internacionales (Red Natura-2000, Reservas de la Biosfera, ...), junto a las labores de puesta en valor desarrolladas en este ámbito por las asociaciones locales, debería ser tenida en cuenta y aprovechada por los agentes sociales implicados para resolver en la medida de lo posible los importantes conflictos que aquejan en la actualidad a este territorio y que tienen que ver, como ya se ha indicado, con la dinámica reciente de este espacio y la incompatibilidad de usos promovidos por las diferentes administración implicadas (espacios naturales protegidos, actividades ganaderas tradicionales, estación de esquí).

\section{BIBLIOGRAFÍA}

\section{V.1. Trabajos científicos y divulgativos}

ACADÉMIE DES SCIENCES (1836): «Géographie Physique-Source au sommet d'une montagne des Asturies». Comptes Rendus Hebdomadaires des Séances de l'Académie des Sciences, Séance du lundi 11 avril 1836, 376. 
ÁLVAREZ RUBIO, J. (2004): Aventureros del tiempo. Leyenda de caminos y de poderosas razones para viajar. Trabajo del Camino (León), Edilesa.

ASENJO, E. (s.f.): «Fotos antiguas de Leitariegos» en Nevasport. Disponible en http://www. nevasport.com/miniestaciones/web/web/curiosidades/leitariegos/leitariegos.html

BARTHES, R. (1957) : Mythologie. Paris, Éditions du Seuil.

BÉGHAIN, P. (1998): Le patrimoine: culture et lien social. Paris, Presses de Science Po (La Bibliothèque du citoyen).

BÉGHAIN, P. (2012): Patrimoine, politique et société. París, Presses de Sciences Po I La Bibliothèque du citoyen.

BELLO, L. (1926): Viaje por las Escuelas de España. Madrid, Magisterio Español.

BERDOULAY, V. (1992): «Les valeurs géographiques» en Encyclopédie de Géographie (Bailly, A., Ferras, R. y Pumain, D., Ed.). Paris, Economica, 385-403.

BERDOULAY, V. (2004): «Requalification des lieux et des espaces publics à travers la réinvention des rapports à la nature». Hégoa, $\mathrm{n}^{\circ}$ 24, 9-10.

BOUISSET, C. y DEGRÉMONT, I. (2010): «Patrimoines Naturels». Sud-Ouest Européen. Revue Géographique des Pyrénées et du Sud-Ouest, $\mathrm{n}^{\circ}$ 30, 1-3.

BOUISSET, C., DEGRÉMONT, I. y SEVILLA, J. (2010): «Le patrimoine naturel vu du web: discours, valeurs, fonctions». Sud-Ouest Européen. Revue Géographique des Pyrénées et du Sud-Ouest, $\mathrm{n}^{\circ}$ 30, 85-98.

BOZONNET, J-P. (1992): Des monts et des mythes. Imaginaire social de la montagne. Grenoble, Presses Universitaires de Grenoble.

CARVALLO, L.A. de (1695): Antigüedades y cosas memorables del Principado de Asturias. Madrid, Julián Paredes.

CASTAÑO, R. (1984): Anexo al Plan de explotación a cielo abierto en el paraje "El Pando" del término de Caboalles de Abajo, Ayuntamiento de Villablino (León). Plan de Restauración. Disponible en http://info.igme.es/SidPDF\%5C038000\%5C436\%5C38436_0001.pdf.

CASTAÑÓN, J.C. y FROCHOSO, M. (2007): «La naturaleza del paisaje en el Parque Nacional de los Picos de Europa» en La conservación del paisaje en los parques nacionales (Martínez de Pisón, E. y Ortega, N., Dir.). Madrid, Universidad Autónoma de Madrid, Fundación Duques de Soria, 177-212.

CASTAÑÓN, J.C. y QUIRÓS, F. (2004): «La contribución de Bory de Saint-Vincent (17781846) al conocimiento geográfico de la Península Ibérica: Redescubrimiento de una obra cartográfica y orográfica olvidada». Ería: Revista cuatrimestral de geografía, no 64-65, 177-205.

CONSEJO DE EUROPA (2000): Convenio Europeo del Paisaje. Florencia, Consejo de Europa.

DAMERY, C. (2004): «Le lieu patrimonial ou la rencontre du visiteur avec la patrimoine natural». Hégoa, n $^{\circ} 24,11-18$.

DEBARBIEUX, B. (2008): «Construits identitaires et imaginaires de la territorialité : variations autour de la figure du montagnard». Annales de géographie, $\mathrm{n}^{\circ}$ 660-661, 90-115.

DEGRÉMONT, I. (1998): «Patrimoine et zone littorale, un renouveau des enjeux touristiques dans les Pyrénées Atlantiques». Sud-Ouest Européen, n 1, 33-46.

DÍEZ, F. A. (1946): Laciana. Memoria de su antiguo y patriarcal Concejo. Madrid, Publicaciones del Instituto de Estudios de Administración Local. 
ESPEJO, C. (2011): «El paisaje como recurso turístico» en Retos y perspectivas de la gestión del paisaje en Canarias (Simancas, M.R. y Cortina, A., coord..). Gobierno de Canarias, Observatorio del Paisaje de Canarias, 437-462.

FERNÁNDEZ, V. (2013): «Los paisajes de interés cultural de Asturias». Ería, nº 64-65, 177-205.

GAY, J. (1958): «Viaje botánico de Durieu por Asturias, emprendido en el año 1935, de Jacques Gay, traducción y notas, por José Antonio Jáuregui, S.J.». Boletín del Instituto de Estudios Asturianos (Suplemento de Ciencias), Año IV, núm. VI, 31-98.

GÓMEZ, J. (2013): «Del patrimonio paisaje a los paisajes patrimonio». Documents d'Anàlisi Geogràfica, vol. 59/1, 5-20.

GONZÁLEZ, D. (2011): «Vías romanas de montaña entre Asturias y León. La integración de la Asturia Transmontana en la red viaria de Hispania». Zephyrus, LXVII, 171-192.

GONZÁLEZ, J. (2011): «Jovellanos en Cangas. Relato de su estancia en Cangas del Narcea en la vendimia de 1796» en El Tous p@ Tous. Sociedad Canguesa de Amantes del País. Disponible en http://www.touspatous.es/index.php/historia/1030-jovellanos-en-cangasrelato-de-su-estancia-en-cangas-del-narcea-en-la-vendimia-de-1796.html

GRUPO ECOLOGISTA CANGUÉS AZOR (GECA) (2012): Guía del Camín Real de L.Leitariegos en Asociación GECA. Disponible en https://asociaciongeca.wordpress. com/2012/10/25/camin-real-leitariegos/

GUILLAUME, M. (1990): «Invention et stratégies du patrimoine» en Patrimoines en folie (Jeudy, H.P., Dir.). París, Ministère de la Culture et de la Communication, Cahier 5, Édition de la Maison des Sciences de l'Homme, 12-20.

HERNÁNDEZ-PACHECO, E. (1914): «Fenómenos de glaciarismo cuaternario en la cordillera cantábrica. Carbonífero stefaniense en Cangas de Tineo». Boletín de la Real Sociedad Española de Historia Natural, tomo XIV, 407-408.

HERNÁNDEZ-PACHECO, F. (1929): «Datos sobre Geología asturiana (Leitariegos y Somiedo)». Boletín de la Real Sociedad Española de Historia Natural, tomo XXIX, 295-296.

HERNÁNDEZ-PACHECO, F. (1930) : «Por los puertos de la cordillera cantábrico-astúrica : de Leitariegos a Somiedo y los lagos». Peñalara Revista Ilustrada de Alpinismo, 172-181.

JOVELLANOS, G.M. de (1999): Obras completas, Tomo VII: Diario $2^{\circ}$ (Cuadernos V, conclusión, VI y VII), edición dirigida por José Miguel Caso González. Oviedo, Centro de Estudios del Siglo XVIII, Gijón, Ayuntamiento de Gijón.

KRÜGER, F. (1948): «Las Brañas. Contribución a la historia de las construcciones circulares en la zona astur-galaico-portuguesa». Boletín del Instituto de Estudios Asturianos, Año III, $\mathrm{n}^{\circ} 8,41-98$.

LLANO, A. de (1928): Bellezas de Asturias de Oriente a Occidente. Oviedo, Excelentísima Diputación Provincial.

LÓPEZ, L. (1979): «La montaña leonesa, del balneario al esquí». Estudios Humanísticos, $\mathrm{n}^{\mathrm{o}} 1,135-138$.

LÓPEZ, J. (2015): “Asturias, José Rodríguez Riesco y Leitariegos” en Leitariegos en 1898 (Rodríguez, J.). Estudio y edición de Juaco López Álvarez con un prólogo de Francisco Rodríguez. Cangas del Narcea, Asociación Tous Pa Tous, 11-27. 
LÓPEZ, J. (s.f. a): «Padre Luis Alfonso de Carvallo, 1571 (Entrambasaguas, Cangas del Narcea)- 1635 (Villagarcía de Campos, Valladolid)»en El Tous p@ Tous. Sociedad Canguesa de Amantes del País. Disponible en http://www.touspatous.es/index.php/biografias/996iquien-fue-el-padre-carballo.html

LÓPEZ, J. (s.f. b): «Ramón García Redruello y Cangas del Narcea» en El Tous p@ Tous. Sociedad Canguesa de Amantes del País. Disponible en http://www.touspatous.es/index. php/literatura/1053-ramon-garcia-redruello-y-cangas-del-narcea.html

MADERUELO, J. (2007) : «Paisaje: un término artístico» en Paisaje y Arte (Maderuelo, J., ed.). Huesca, Abada Editores, 11-36.

MARTÍ, J. (1986): «La pasión por la montaña. Literatura, pedagogía y ciencia en el excursionismo del siglo XIX». Geocrítica, $\mathrm{n}^{\circ} 66,1-48$.

MARTÍNEZ, L.C. y SEVILLA, J. (2013): «Al encuentro de "geografía” en el arte: los paisajes de la Montaña Central de Asturias». Liño, n 19, 81-94.

MARTÍNEZ DE PISÓN, E. (2004) : «200 años de pirineísmo» en Parques Nacionales de Montaña (Anía, E., García, M., Tornos, A., Viñuales, E., Dir.). Madrid, Ministerio de Medio Ambiente, Organismo Autónomo de Parques Nacionales, 59-65.

MARTÍNEZ DE PISÓN, E. y ÁLVARO, S. (2002): El sentimiento de la montaña. Doscientos años de soledad. Madrid, Desnivel.

MELÉNDEZ DE ÁRVAS, F. (1897): «Leitariegos» en Asturias: Su historia y monumentos. Bellezas y recuerdos. Costumbres y tradiciones. El bable. Asturianos ilustres. Agricultura e industria. Estadística (Bellmunt, O. y Canella, F., Dir.). Gijón, Fototipia y Tipografía de O. Bellmunt, 193-222.

MOLLÁ, M. (2010): «La Sierra de Guadarrama y los excursionistas alemanes» en Lenguajes y visiones del paisaje y del Territorio (Ortega, N., García, J. y Mollá, M., Dir.). Madrid, Ediciones de la Universidad Autónoma de Madrid, Colección de estudios, n 141, 55-60.

MORÁN, C. (1925): Por Tierras de León (Historia, costumbres, monumentos, leyendas, filología y arte). Salamanca, Establecimiento Tipográfico de Calatrava.

OCAMPO, J. (2013): «Leitariegos/Alsa/China: Cosmen, una dinastía empresarial centenaria» en Empresas y empresarios asturianos. El caso Alsa (Ocampo, J., Dir.). Gijón, Ediciones Trea, Fundación Valdés-Salas, 13-74.

ORTEGA, N. (2010) : «El lugar del paisaje en la geografía moderna». Estudios geográficos, $\mathrm{n}^{\mathrm{o}} 269$, Madrid, 367-393.

PÉREZ, M. (1998): «Juventud y deporte en Cangas del Narcea entre 1960 y 1978-Recuerdos de mi época de dirigente juvenil en Cangas»en El Tous p@ Tous. Sociedad Canguesa de Amantes del País. Disponible en http://www.touspatous.es/index.php/deportes/1323juventud-y-deporte-en-cangas-del-narcea-entre-1960-y-1978.html?start=1

PRINCIPADO DE ASTURIAS (2013): «Decreto 67/2013, de 28 de agosto, por el que se establecen los órganos de gestión de la reserva de la Biosfera de Muniellos y su composición». Boletín Oficial del Principado de Asturias, núm. 210 de 10-IX-2013, $1-2$.

POULOT, D. (1998): «Le patrimoine et les aventures de la modernité» en Patrimoine et modernité (Poulot, C., Dir.). París, L'Harmattan, coll. Chemins de la mémoire, 7-67.

RABANAL, M.A. (1984). «Vías de la época romana entre Asturias y León». Memorias de Historia Antigua, $\mathrm{n}^{\circ}$ 6, 137-154. 
REDONDO, J.M. (1988): Las minas de carbón a cielo abierto en la provincia de León: transformación del medio y explotación de recursos no renovables. León, Secretariado de Publicaciones de la Universidad de León, Consejería de Cultura y Bienestar Social de la Junta de Castilla y León.

RIVAS, S. y RIVAS, S. (1959): «Una visita a la laguna de Arvas (Leitariegos). Nuevas comunidades de Litorelletea y Scheuchzerio-Caricetea fuscae». Anales del I. Botánico A.J. Cavanilles, $\mathrm{n}^{\circ} 16,566-586$.

RODRIGO, J.M. et al. (2012): «Registro de paisajes de interés cultural de Andalucía. Criterios y metodología». Revista ph. Instituto Andaluz del patrimonio Histórico, $\mathrm{n}^{\circ} 81$, 64-75.

RODRÍGUEZ, F. (2015): “El Marqués de Brañas” en Leitariegos en 1898 (Rodríguez, J.). Estudio y edición de Juaco López Álvarez con un prólogo de Francisco Rodríguez. Cangas del Narcea, Asociación Tous Pa Tous, 7-10.

RODRÍGUEZ, J. (1900): «Leitariegos» en Asturias: Su historia y monumentos. Bellezas y recuerdos. Costumbres y tradiciones. El bable. Asturianos ilustres. Agricultura e industria. Estadística (Bellmunt, O. y Canella, F., Dir.). Gijón, Fototipia y Tipografía de O. Bellmunt, 181-184.

ROJO, J. (1979-1980): «Noticia de Luis Bello (1872-1935) y de su libro "Viaje por las escuelas de España"». Archivum: Revista de la Facultad de Filología, 115-144.

RUBIO, A. (1954): Reseña físico-geológica del valle de Laceana. Provincia de León. Madrid, Imprenta de Julio Soto.

RUIZ DE LA PEÑA, J.I. (1979): «El coto de Leitariegos. Una comunidad de montaña en la Asturias medieval». Asturiensia Medievalia, nº3, 173-216.

SANTOS, J. (s.f.): «Valle de Laciana» en Las Reservas de la Biosfera Españolas. Disponible en: http://rerb.oapn.es/index.php/red-espanola-de-reservas-de-la-biosfera/lasreservas-de-la-biosfera-espanolas/1-2-1-mapa/valle-de-laciana/descripcion-general

SANTOS, N. (1988): «Vías de comunicación de época romana en el valle del río Narcea (concejo de Cangas de Narcea)». Boletín del Real Instituto de Estudios Asturianos, $\mathrm{n}^{\circ}$ 42 (127), 615-640.

SAULE-SORBÉ, H. (2007): «El Parque Nacional de los Pirineos y el Arte» en La conservación del paisaje en los parques nacionales (Martínez de Pisón, E. y Ortega, N., Dir.). Madrid, Universidad Autónoma de Madrid, Fundación Duques de Soria, 125-176.

SCHRADER, F. (1879). «Les clubs alpins». Communication adressée à la Société dans sa séance du 7 mars, 55-60.

SERRANO, E. (2012): «Montañas, paisaje y patrimonio». Nimbus, n 29-30, 701-718.

SEVILLA ÁLVAREZ, J. y RODÍGUEZ PÉREZ, C. (2015): «La dinámica reciente del paisaje del puerto de Leitariegos (montaña occidental asturleonesa) a través de la fotografía aérea». Ería. Revista Cuatrimestral de Geografía, nº98, 241-274.

STICKEL, R. (1929): «Observaciones de morfología glaciar en el NO. de España». Boletín de la Real Sociedad Española de Historia Natural, tomo XXIX, nº8, 297-314.

TEICHMAN, A. (1926): «Por la montaña cantábrico-astúrica: desde Oviedo al Puerto de Leitariegos». Peñalara Revista Ilustrada de Alpinismo, Año XIII, n 150 y 151, 105108 y $125-129$. 


\section{V.2. Prensa y crónica}

\section{- Diario de León}

«Muchos proyectos: Federación de la cancha de tenis, más salidas a la nieve y competiciones con otras sociedades». Diario de León, 22 de enero de 1958, 12.

«Excursionismo». Diario de León, 26 de enero de 1959, 5.

«Campaña de esquí 1963-64». Diario de León, 30 de noviembre de 1963, 3.

«En alza el deporte blanco». Diario de León, 23 de abril de 1970, 10.

«Actividades de la Peña de Montañeros Catoute». Diario de León, 13 de enero de 1972, 10.

«Tele-arrastre para Leitariegos». Diario de León, 11 de octubre de 1972, 10.

- El Distrito Cangués

«Expedición científica».El Distrito Cangués, 22 de agosto de 1914, 6.

- El Tous p@Tous. Sociedad Canguesa de Amantes del País

«Historia del Deporte en Cangas del Narcea» en El Tous pa Tous. Sociedad Canguesa de Amantes del País, 2 de marzo de 2014. Disponible en http://www.touspatous.es/index. $\mathrm{php} /$ noticias-contemporaneas/deportes/1322-historia-del-deporte-en-cangas-del-narcea. html

- La Maniega Boletín del «Tous pa Tous»

«Al Cueto de arbas». La Maniega Boletín del «Tous pa Tous», Año III, n ${ }^{\circ}$ 15, agosto de 1928, 11.

«Sección de noticias». La Maniega Boletín del «Tous pa Tous», Año V, n ${ }^{\circ} 28$, septiembreoctubre de 1930, 23-24.

«Excursionistas». La Maniega Boletín del «Tous pa Tous», Año VI, n 33, julio-agosto de $1931,21$.

«Acampados al pie de la laguna del puerto». La Maniega Boletín del «Tous pa Tous», Año VI, no 34, septiembre-octubre de 1931, 22.

- La Voz

García, R. (1925): «El puerto de Leitariegos». La Voz, 11 de septiembre de 1925.

- Narcea

«Una excursión a la laguna del puerto». Narcea, Año I, nº 4, septiembre de 1935, 7.

- Proa

«Viaje a Leitariegos de la O.J.E.». Proa, 25 de febrero de 1968, 10.

«I Campeonato inter-valles de esquí de Leitariegos». Proa, 28 de febrero de 1968, 11.

«Se celebró en Sahagún la primera Asamblea de los C.I.T. de la provincia». Proa, 19 de junio de 1970, 6 .

«Promoción turística del Puerto de Leitariegos». Proa, 22 de julio de 1970, 10.

«Inauguración de un albergue en Leitariegos». Proa, 7 de octubre de 1973, 7. 